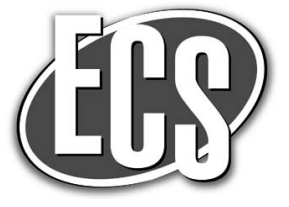

\title{
Photoelectron Spectroscopy for Lithium Battery Interface Studies
}

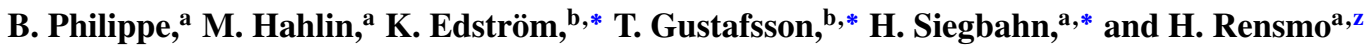

${ }^{a}$ Department of Physics and Astronomy, Uppsala University, SE-751 21 Uppsala, Sweden

${ }^{b}$ Department of Chemistry - Ångström Laboratory, Uppsala University, SE-751 21 Uppsala, Sweden

\begin{abstract}
Photoelectron spectroscopy (PES) has become an important tool for investigating Li-ion battery materials, in particular for analyzing interfacial structures and reactions. Since the methodology was introduced in the battery research area, PES has undergone a dramatic development regarding photon sources, sample handling and electron energy analyzers. This includes the possibility to use synchrotron radiation with increased intensity and the possibility to vary the photon energy. The aim of the present paper is to describe how PES can be used to investigate battery interfaces and specifically highlight how synchrotron based PES has been implemented to address different questions useful for the development of the Li-ion batteries. We also present some recent developments of the techniques, which have the potential to further push the limits for the use of photoelectron spectroscopy in battery research.

(C) The Author(s) 2015. Published by ECS. This is an open access article distributed under the terms of the Creative Commons Attribution Non-Commercial No Derivatives 4.0 License (CC BY-NC-ND, http://creativecommons.org/licenses/by-nc-nd/4.0/), which permits non-commercial reuse, distribution, and reproduction in any medium, provided the original work is not changed in any way and is properly cited. For permission for commercial reuse, please email: oa @electrochem.org. [DOI: 10.1149/2.0051602jes] All rights reserved.
\end{abstract}

Manuscript submitted June 26, 2015; revised manuscript received October 13, 2015. Published November 14, 2015.

A classical Li-ion battery system is composed of a positive and a negative electrode able to reversibly host lithium. The electrodes are immersed in an electrolyte (lithium salt in an organic solvent) while a separator prohibits direct contact between the two electrodes, see Figure 1a. ${ }^{1-5}$ Over the last decades, various electrodes materials have been investigated and an overview of the materials investigated as positive, negative electrode or electrolytes can be found in various recent reviews. ${ }^{6-8}$

Further development of the battery chemistry requires understanding of the fundamental properties of the components and how it relates to their functionality in an operating device. Specifically, it is becoming more and more crucial to better understand the properties of the interface regions between the different battery components, since the interfacial chemistry is closely linked to battery behaviors such as self-discharge properties, safety and cycling stability.

At the interface between the host material and the electrolyte side reactions occur and specifically at potentials outside the thermodynamic stability window of the electrolyte. For electrochemical potentials below about $0.8 \mathrm{~V}$ vs. $\mathrm{Li}^{+} / \mathrm{Li}$, most organic solvents are thermodynamically unstable and a passivating SEI (Solid Electrolyte Interphase $^{9}$ ) layer is formed at the negative electrode/electrolyte boundary. Side products observed at the positive electrode/electrolyte interfaces are referred as to SPI (Solid Permeable Interphase) layer. ${ }^{10}$ The chemical compositions of the surface layers are different for the negative and the positive electrode materials and while thick SEI ( $\sim 30-100 \AA)$ is formed on negative electrode materials, the SPI formed on the positive electrode materials is mostly much thinner (5-10 A) as illustrated in Figure $1 b .^{11-16}$

Photoelectron spectroscopy (PES) displays several of the desirable features to investigate Li-ion battery interfacial chemistry. These features are foremost a controllable surface sensitivity, in the range of the interphase layer thicknesses, in combination with the composition sensitivity. The aim of the present article is to describe among various examples taken from our investigations, how PES can be successfully used to characterize host material and interphase materials chemistries including the SEI and SPI as well as the negative and positive electrodes. Most of the photoelectron spectroscopy investigations to date have used home laboratory $\mathrm{AlK} \alpha$ and/or He(II) (XPS or UPS) photon sources. The present paper will focus largely on the opportunities with synchrotron radiation used over a broad energy ranging from the soft $\mathrm{X}$-ray regime of a few hundred $\mathrm{eV}$ to the harder $\mathrm{keV}$ energies.

\footnotetext{
*Electrochemical Society Active Member.
}

${ }^{\mathrm{z}}$ E-mail: hakan.rensmo@physics.uu.se

\section{Photoelectron Spectroscopy (PES) on Battery Electrodes}

General principles of PES. - The fundamental expression of PES is the Einstein photoelectric law:

$$
\mathrm{E}_{\text {Kinetic }}=\mathrm{h} \nu-\mathrm{E}_{\text {Binding }}
$$

where $E_{\text {Kinetic }}$ is the kinetic energy of the electron expelled from the material by the photon with energy $h \nu$ and $E_{\text {Binding }}$ is the binding energy of the electron in the material. Binding energies for condensed phase samples are normally referred to the Fermi level, thus:

$$
\mathrm{E}_{\text {Binding }}^{\mathrm{F}}=\mathrm{E}_{\text {Binding }}-\Phi_{\text {sample }}
$$

where $\Phi_{\text {sample }}$ is the work function of the sample.

Using a fixed photon energy, core levels appear as peaks in the measured electron spectrum, whose positions on the binding energy scale are both element specific as well as dependent on the chemical state of the element in the material. Calibration of photoelectron spectra are generally made with respect to reference peaks of known binding energies. Depending on the atomic environment of the species studied for the present battery systems, this can either be done with respect to substrate levels or levels associated with the SEI overlayer. For the detailed calibration procedures used in the different examples discussed in this paper, we refer to the original papers.

The intrinsic surface sensitivity of PES is due to the short mean free path of the electrons in the material. The X-rays of the incident beam penetrate several hundreds of nanometers through the material, whereas the ejected electrons in the spectral peaks have a very short inelastic mean free path and only originate in the first few nanometers of the material. Figure 2 shows the so-called universal curve, i.e. the general behavior of the inelastic mean free path (IMFP) of an electron vs. its kinetic energy. As can be seen, for the traditional lab X-ray photon source using $\mathrm{AlK} \alpha$ at $1487 \mathrm{eV}$, the inelastic mean free path for most core levels varies between 5-25 A. PES methods using lab sources such as $\mathrm{AlK} \alpha$ have thus become standard tools in the battery community.

The use of photoelectron spectroscopy for battery purposes has been intimately related to the development of sample handling techniques, photon sources and electron spectrometers. In particular, synchrotron radiation based photoelectron spectroscopy offers here new opportunities allowing for interface studies approaching in-situ conditions. The use of synchrotron radiation for photoelectron spectroscopy implies a number of important advantages compared to characteristic lab sources such as $\mathrm{AlK} \alpha$. The beam intensities are significantly larger due to advanced insertion devices in the synchrotron storage rings allowing faster measurements and better resolution. The photon energies can also be tuned to desired values within wide ranges. For a particular beam-line, constraints in the monochromator configuration limit the energy range that can be used. Soft X-ray beam-lines are equipped 


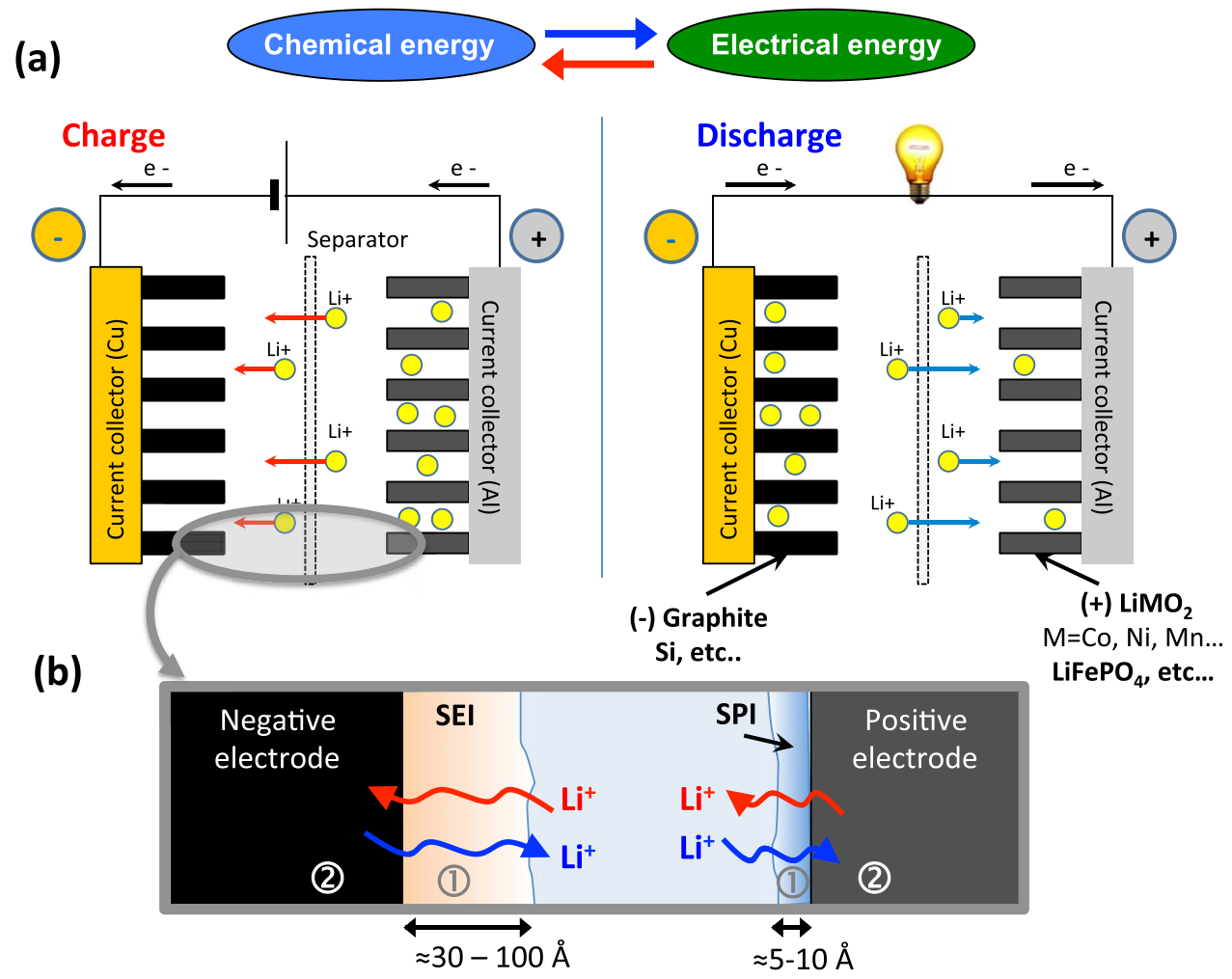

Figure 1. (a) Schematic representation of the operating principle of a Li-ion battery. (b) Zoom on the electrode/electrolyte interphases with the SEI (Solid Electrolyte Interphase) and the SPI (Solid Permeable Interphase) present at the surface of the negative and positive electrode respectively.

with grazing incidence grating monochromators, while for beam-lines providing photon energies above $2000 \mathrm{eV}$ crystal monochromators are required.

When synchrotron based methods were introduced, the possibility to measure core levels with photon energies in the range below $\mathrm{AlK} \alpha$ $(\mathrm{h} v=1487 \mathrm{eV})$ was an important new ingredient, allowing for detailed control of the surface sensitivity. To differentiate from recent developments at harder X-ray energies, measurements using photon energies below $2000 \mathrm{eV}$ will in the present paper be referred to as SOXPES (SOft X-ray Photoelectron Spectroscopy). The recent development has been the extension of the photon energies up to $10 \mathrm{keV}$ and is commonly referred to as HAXPES (HArd X-ray Photoelectron Spectroscopy). This implies that interfacial modifications during cycling are accessible down to probing depths of $100 \AA-500 \AA$.

Sample handling. - There are several different approaches for conducting experiments for the study of electrode/electrolyte interfaces in Li-ion batteries. Ideally, one would like to study the electronic structure and interfaces of battery materials in situ/in operando but this poses experimental challenges that are not easy to meet. Lithium is stable in pure oxygen gas while it is highly reactive in presence of moisture or $\mathrm{CO}_{2}$. The effect on the surface when exposed to air can (a)

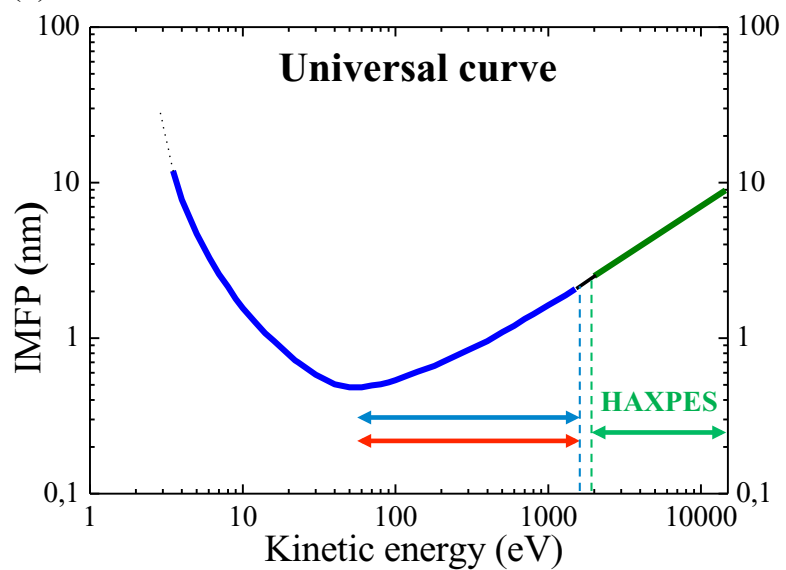

(b)

\begin{tabular}{|c|}
\hline $\begin{array}{c}\text { In-house XPS } \\
\mathrm{h} v=1487 \mathrm{eV} \\
\mathrm{E}_{\text {kin }} \sim 100-1487 \mathrm{eV} \\
E_{\text {kin }} \text { fixed for each core peak }\end{array}$ \\
\hline \hline$\underline{\text { SOXPES: }}$ MAX IV \\
$\mathrm{h} v=50-1500 \mathrm{eV}$ \\
$\mathrm{E}_{\text {kin }} \sim 100-1500 \mathrm{eV}$ \\
$E_{\text {kin }}$ tunable for each core peak \\
\hline \hline HAXPES: Bessy II \\
$\mathrm{h} v=2000-10,000 \mathrm{eV}$ \\
$\mathrm{E}_{\text {kin }} \sim 100-10,000 \mathrm{eV}$ \\
$E_{\text {kin }}$ tunable for each core peak \\
\hline
\end{tabular}

Figure 2. (a) Universal curve representing the Inelastic Mean Free Path (IMFP) as a function of the kinetic energy of the photoelectrons. (b) Illustration of the energy range ( $h v$ and $E_{k}$ ) reached by using monochromatic $(A l K \alpha)$ or synchrotron (Soft X-ray and Hard X-ray) sources. For a particular beam-line, constraints in the monochromator configuration limits the accessible energy range. Soft X-ray beam-lines are equipped with grazing incidence grating monochromators, while for photon energies above $2000 \mathrm{eV}$ crystal monochromators are required. 

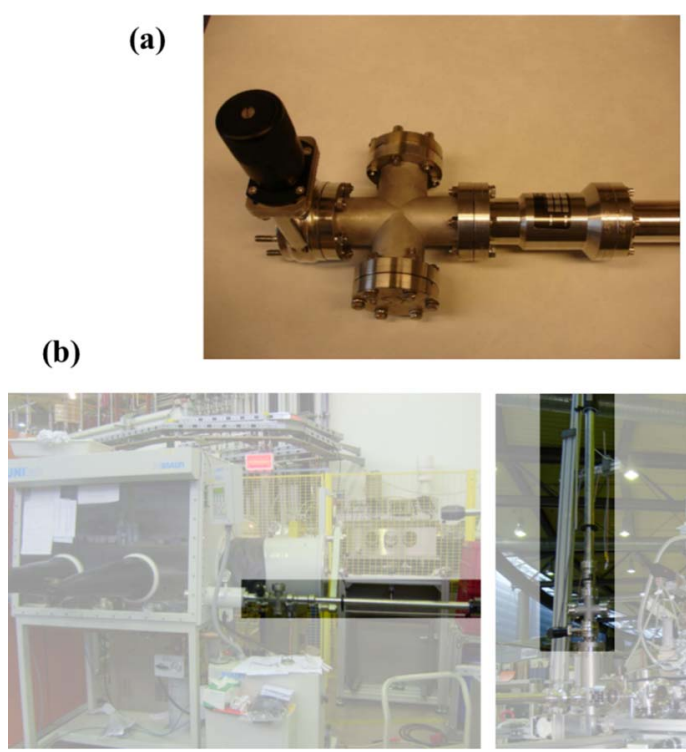

Connection to the glovebox

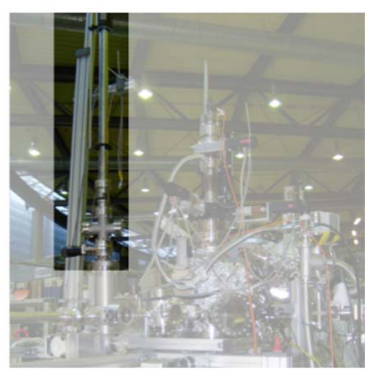

Connection to the spectrometer

Figure 3. (a) Picture of the portable magnetic transfer rod (b) Pictures of the magnetic transfer rod when connected to a glove box (on the left) and when connected to a PES instrument (on the right).

lead to an over-estimation of some surface compounds present in the SEI layer such as $\mathrm{Li}_{2} \mathrm{CO}_{3}, \mathrm{Li}_{2} \mathrm{O}$ and $\mathrm{LiF}$. For example, the reaction between the common electrolyte salt $\mathrm{LiPF}_{6}$ with water can lead to the formation of species such as HF formed according to the reaction:

$$
2 \mathrm{LiPF}_{6}+\mathrm{H}_{2} \mathrm{O}=\mathrm{Li}_{2} \mathrm{O}+2 \mathrm{PF}_{5}+2 \mathrm{HF}
$$

Therefore, when studying the thin anode SEI and cathode SPI-layers formed during cycling of a real Li-ion battery using PES, the battery needs to be taken apart in inert atmosphere (Ar-filled glove box) and transferred to a spectrometer in a protected vessel. This means that most knowledge we have so far of cycling of real Li-ion batteries using PES is based on ex-situ post-mortem experiments. Some commercial PES instruments are equipped with special transfer chambers where samples can be handled in a controlled environment. However, these systems are not easily adapted to fit the specific instrumentation used at synchrotron facilities. For more general purposes, such as instrumentation used at synchrotron facilities, one may use transfer systems for moving samples directly between an Ar filled glove box to any vacuum instrument without exposing the samples to air. In the version designed by us (Figure 3) the device is built up in two parts; a portable unit consisting of a magnetic transfer rod mounted on a small vacuum chamber with a valve at the front end, and an O-ring sealed adapter used between the portable unit and the glove box. The portable unit can thus, apart from being mounted to the adapter, also be mounted directly on the load lock of the PES instrument. The process can also be reversed for continued electrochemical treatment without air exposure.

After introduction of an electrode into the spectrometer, the volatile compounds present at the surface of the sample are pumped off and the most stable compounds present on the electrode surfaces remain. Generally, these remaining parts are considered to represent the SEI or SPI layers together with traces of electrolyte residues. The residues can contribute to the spectra both in terms of attenuation of the signals from the electrode as well as with unwanted extra peaks obscuring the information of the relevant electrode peaks. A common way to remove electrolyte residues is to perform a post-rinsing of the cycled electrode using a volatile solvent prior to the PES measurement. It is important to realize that washing and vacuum conditions may induce changes in the electrode interfacial layers, and thus only samples that have received a similar post-treatment should be compared to each (a)
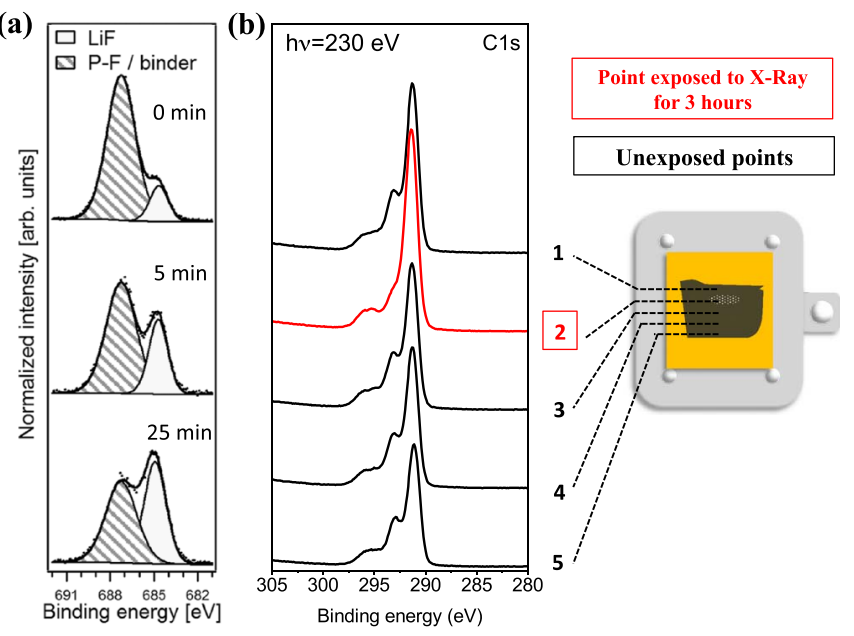

Figure 4. Examples of radiation damage induced by x-rays. (a) F1s spectra of a graphite electrode fresh, after 5 and $25 \mathrm{~min}$ of exposure. Adapted from Ref. 22 (b) C1s spectra of a washed Si composite electrode after $3 \mathrm{~h}$ of exposure (in red), the black spectra were recorded on fresh spots.

other. These effects have been systematically investigated for lithium insertion in graphite. ${ }^{17}$

Measurement and data interpretation: common issues and artefacts. - The chemical reactions within the SEI during cycling create a non-uniform interphase region. Depth profiling of this layer containing both soft and hard matter such as alkylcarbonates and different polymers combined with inorganic salts as is the case in the SEI is nontrivial and prone to misinterpretation. Results based on $\mathrm{Ar}^{+}$ etching must be used with caution due to the risk of inducing side reactions during the experiment leading to an overestimate of $\mathrm{LiF}$, $\mathrm{Li}_{2} \mathrm{CO}_{3}$ and $\mathrm{Li}_{2} \mathrm{O}$ on the surface. ${ }^{13,18}$ Angular resolved depth profiling is a common tool for studying the chemical gradient in smooth surfaces such as stainless steels. ${ }^{19}$ For rough surfaces and complex morphology such as SEI and SPI on battery electrodes this technique is of more limited use. Utilizing the fact that the surface sensitivity of a PES measurement can be varied by tuning the photon energy, a non-destructive depth characterization of the SEI may be obtained. As will be discussed below, such a methodology has been shown to give reliable and new information about the chemical gradients of the SEI on typical anode materials such as graphite ${ }^{20}$ and silicon. ${ }^{21}$

Due to the formation of non-conducting compounds on the surface of the electrode during cycling of the battery $\left(\mathrm{LiF}, \mathrm{Li}_{2} \mathrm{CO}_{3}\right.$ etc. $)$ sample charging can often give broad and featureless spectra that are difficult to resolve and calibrate. An appropriate practice to check for such effects is to perform quick-scan reference recordings before and after the data acquisition of each peak. Caution must also be exercised in relation to the occurrence of inhomogeneous charging for these composite films as well as radiation damage. It is crucial to estimate the sensitivity of the battery sample to radiation damage and estimate the rate of change to establish a consistent and accurate measurement protocol. Figure 4 shows how radiation damage can locally impact the sample and the resulting spectra. ${ }^{22}$

\section{Lithium Battery Interface Studies}

This section highlights examples of PES applied to battery research. Specifically it highlights how synchrotron based PES has been implemented to address different questions useful for the development of the Li-ion batteries. The first part of this section, Battery interphase layers, focuses on the use of PES to investigate the interphase layers and the second part, Properties of battery electrode materials, is devoted to the characterization of the active host material. 
Battery interphase layers.-The SEI formation on lithium and graphite. - Firstly described by E. Peled in $1979,{ }^{23}$ the formation of a surface layer, called SEI, was observed on a lithium metal immersed in an electrolyte and several models for this interphase was proposed. ${ }^{24-26}$ The first PES studies appeared in 1999 but the SEI had previously been studied with FTIR providing extensive knowledge about the SEI. ${ }^{27,28}$ At that time the SEI was pictured as a heterogeneous layer of both inorganic and organic species. The organic component was found to be a mixture of alkyl carbonates and polymer type compounds and the inorganics included $\mathrm{LiF}, \mathrm{Li}_{2} \mathrm{O}, \mathrm{LiOH}$ and $\mathrm{Li}_{2} \mathrm{CO}_{3}$ as well as different reduction products of the lithium salt compounds. It was also shown that the kind of organic solvent used in the electrolyte influenced the SEI composition. For EC-based electrolytes it was suggested to contain mainly $\left(\mathrm{CH}_{2} \mathrm{OCO}_{2} \mathrm{Li}\right)_{2}$ including $\mathrm{Li}_{2} \mathrm{CO}_{3}, \mathrm{LiF}$ etc. ${ }^{29}$ In propylene carbonate $(\mathrm{PC})$ based electrolytes, $\mathrm{ROCO}_{2} \mathrm{Li}$ was shown to be the main species. ${ }^{30,31}$

Our early $\mathrm{AlK} \alpha \mathrm{PES}$-studies provided information that the ratio between the different SEI components is highly affected by the lithium salt used in the electrolyte. ${ }^{12}$ Salts such as $\mathrm{LiBF}_{4}$ and the commonly used $\mathrm{LiPF}_{6}$ result in an SEI where inorganic compounds are important parts while graphite cycled with more stable salts such as LiTFSI and lithium triflate will lead to an SEI largely consisting of organic components. It was also shown that the thermal stability of the SEI was dependent on the anion of the lithium salt with $\mathrm{LiBF}_{4}$ giving an SEI that breaks down already at $60^{\circ} \mathrm{C}$ while that of $\mathrm{LiPF}_{6}$ is stable to above $105^{\circ} \mathrm{C}^{32}$

More detailed PES studies of model systems have since then added to the knowledge about the SEI. By studying HOPG (Highly Oriented Pyrolytic Graphite) Peled et al. could show that the inorganic compounds mainly form on the edge-planes while on the basal plane (where the lithium cannot enter the graphite) mainly organic SEI compounds form..$^{33}$ This study has recently been followed by similar studies confirming the earlier results but with a larger precision in their observations. ${ }^{34}$

The introduction of synchrotron based PES offers the opportunity to make measurements with variable surface sensitivity, and thus a non destructive method to scan the composition of the interface layers at different depths. To our knowledge, the first study of the depth profile of a graphite SEI using synchrotron radiation-based photoelectron spectroscopy appeared in 2003. ${ }^{35}$ Below we give further examples of such depth profiling of battery interfaces.

Figure 5 shows an example of depth profiling using both the surface sensitive SOXPES and more bulk sensitive HAXPES to study the SEI of a graphite electrode prepared in a full cell configuration (graphite vs. $\mathrm{LiFePO}_{4}$ ). In the $\mathrm{C} 1 \mathrm{~s}$ spectra the presence of the SEI is clearly observed since the substrate signal can barely be observed at low photon energies (SOXPES at $430 \mathrm{eV}$ and a probing depth of about $2 \mathrm{~nm}$ ), while at higher photon energies the substrate peak is dominating (HAXPES at $6900 \mathrm{~nm}$ and a probing depth of $47 \mathrm{~nm}$ ). The F1s, O1s and $\mathrm{P} 2 \mathrm{P}$ give further insight to the depth profile of the SEI. For example the presence of $\mathrm{Li}_{2} \mathrm{O}$ when using HAXPES shows that $\mathrm{Li}_{2} \mathrm{O}$ can be found deep in the SEI (O1s spectra). The combination of SOXPES and HAXPES on the graphite electrode in this way gives a depth profile including a reliable picture of both the lithiated graphite feature (at $282 \mathrm{eV}$ in the C1s spectra) and its SEI and enables us to suggest the schematic picture of the SEI.

For characterization of the outermost surface region (a few $\mathrm{nm}$ ) the use of different photon energies in the SOXPES regime is particularly valuable since a common kinetic energy and thus the same probing depth for different core levels can be obtained. As an example, in Figure 5 the same kinetic energy (approximately $145 \mathrm{eV}$ ) for the emitted photoelectrons was used by setting different photon energies for different core levels (F1s $835 \mathrm{eV}, \mathrm{O} 1 \mathrm{~s} 680 \mathrm{eV}, \mathrm{C} 1 \mathrm{~s} 430 \mathrm{eV}$ and P2p $280 \mathrm{eV}$ ). At higher photon energies such an adjustment becomes less important and comparisons can be made directly using the same photon energies. The large benefit from the use of HAXPES comes from recording relatively more information from the bulk, and also means of accessing information from core levels that cannot be accessed using classical $\mathrm{Mg} \mathrm{K} \alpha$ and $\mathrm{Al} \mathrm{K} \alpha$ based PES. P1s is one example and together with the $\mathrm{P} 2 \mathrm{p}$ peak this indicates a reaction of $\mathrm{LiPF}_{6}$ forming $\mathrm{a} \mathrm{Li}_{\mathrm{x}} \mathrm{PO}_{\mathrm{y}} \mathrm{F}_{\mathrm{z}}$ compound with increasing amounts deeper in the SEI. To further emphasize the presence of an SEI layer a similar investigation was carried out on the SPI formed on the positive $\mathrm{LiFePO}_{4}$ electrode, also shown in Figure 5. It specifically shows that the active material can also be detected at lower photon energies and thus that the SPI is clearly thinner than the SEI.

Interphase layers formed on other electrode materials..-The interphase layers formed on other electrode materials have also been studied, for example on silicon that, compared to graphite, has a capacity about ten times higher. The Si-Li alloying leads to a large volume expansion during lithiation, which in turn makes fabrication of high quality electrodes difficult due to the cracking and reformation of the SEI during battery cycling.

Using a methodology similar to the graphite case above, the first study of SEI on silicon electrodes using synchrotron radiation based techniques was made by the present authors using both SOXPES and HAXPES. ${ }^{36}$ By investigating a larger number of samples stopped at different potentials during first lithiation it was shown that the SEI on a Si electrode is formed at the very beginning of the first discharge, starting before the lithiation of the silicon. It was also shown that, when using similar electrolytes, the SEI has a composition akin to that observed on lithium or graphite. ${ }^{21}$ Most interestingly, in another study it was shown that its composition remains stable during a long term cycling between $0.9 \mathrm{~V}$ and $0.12 \mathrm{~V} \mathrm{vs} . \mathrm{Li}^{+} / \mathrm{Li}^{37} \mathrm{The} \mathrm{C} 1 \mathrm{~s}, \mathrm{~F} 1 \mathrm{~s}$ and $\mathrm{P} 2 \mathrm{p} / \mathrm{P} 1 \mathrm{~s}$ PES spectra after 100 discharges (lithiated state) are presented in Figure 6. The variation of the $\mathrm{C} 1 \mathrm{~s}$ spectra illustrates the layered structure of the SEI with an outer part mainly consisting of organic materials while the inner part is richer in inorganic species. Very similar results were obtained using this methodology on a conversion electrode material, viz. $\mathrm{Fe}_{2} \mathrm{O}_{3}$. 38

The use of PES over the broad photon energy range available via synchrotron radiation allows detailed depth profiling of the SEI. Although an in-house PES offers less flexibility for SEI investigations, a suitable matching between the SEI layer thickness and probing depth of an in-house spectrometer will also provide a means for in-depth SEI characterization. Examples of this are studies on $\mathrm{MnSn}_{2},{ }^{39} \mathrm{Ni}_{3} \mathrm{Sn}_{4},{ }^{40}$ $\mathrm{Cu}_{6} \mathrm{Sn}_{5}{ }^{41}$ and $\mathrm{TiSnSb}^{42}$ where the SEI layer has been systematically investigated. Interestingly, some investigations of the SEI have highlighted the importance of the initial contact with the electrolyte as an important step where reactions may occur that will influence the future cycling history. This is the case for example for the $\mathrm{Cu}_{6} \mathrm{Sn}_{5}$ electrode where a passivation layer is formed by simple contact with the electrolyte, in contrast to a graphite electrode. Thus, not only pristine and cycled electrodes should be investigated but also electrodes that have only been exposed to the electrolyte.

Compared to the detailed synchrotron based SOXPES/HAXPES studies carried out on the SEI of negative electrodes, fewer synchrotron based investigations of the cathode and its SPI have been reported. As will be discussed in the next section, a reason for this is that the SPI is very thin and traditional PES investigations of the electrodes are thus well matched to study the substrate through the associated SPI. Most PES investigations of cathodes have hence been focused on the host material and the bulk material changes during the electrochemical cycling rather than the SPI. One example of the use of SOXPES to obtain information on the SPI was given in the previous section with $\mathrm{LiFePO}_{4}$ cycled versus graphite. Another recent example is the investigation of the SPI formed on the carbon black (CB) additives commonly used in the positive electrode formulation to increase the electrical conductivity. Decomposition of the electrolyte at the surface of $\mathrm{CB}$ at high voltages up to $4.9 \mathrm{~V}$ was studied by SOXPES and the results revealed partial decomposition of the electrolytes on the $\mathrm{CB}$ electrode in the OCV state, i.e. after a simple storage of a mounted battery without applying external current or voltage. $^{43}$

Among the in-house PES studies focusing on the SPI, we can also mention an early paper on $\mathrm{LiCoO}_{2}, \mathrm{LiNiO}_{2}, \mathrm{LiNi}_{1-\mathrm{x}} \mathrm{Co}_{\mathrm{x}} \mathrm{O}_{2}$, $\mathrm{LiFePO}_{4}{ }^{10}$ or more recently two detailed studies of the aging mechanisms of $\mathrm{LiNi}_{\mathrm{x}} \mathrm{Co}_{\mathrm{y}} \mathrm{Mn}_{\mathrm{z}} \mathrm{O}_{2}$ electrode cycled at high temperature. ${ }^{44,45}$ 


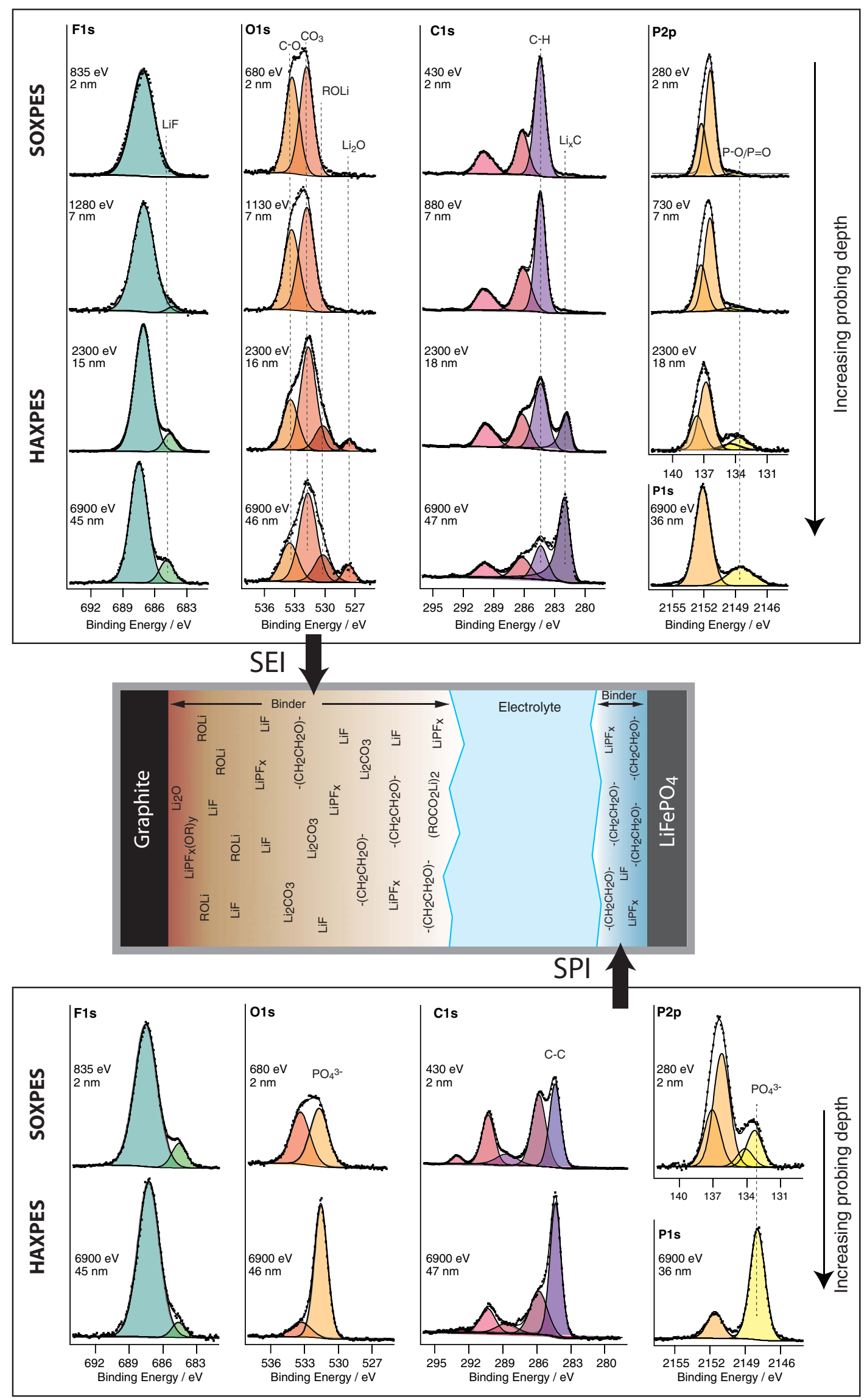

Figure 5. Lithiated graphite (top) and delithiated $\mathrm{LiFePO}_{4}$ (bottom) PES spectra ( $\mathrm{F} 1 \mathrm{~s}, \mathrm{O} 1 \mathrm{~s}, \mathrm{C} 1 \mathrm{~s}$ and $\mathrm{P} 2 \mathrm{p}$ ) presented as a function of the excitation energies i.e. the probing depth and resulting schematic of the SEI and SPI. Adapted from Ref. 20. 
(a) $\mathrm{C} 1 \mathrm{~s}$

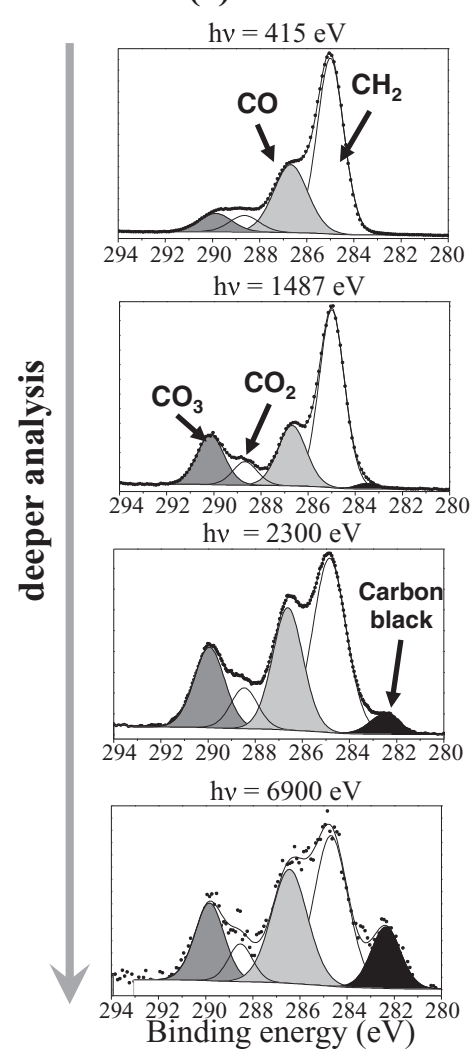

(b) F1s

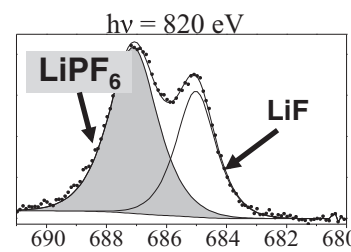

$\mathrm{hv}=1487 \mathrm{eV}$

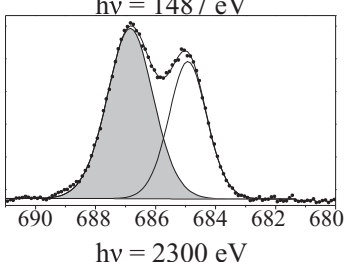

hv $=2300 \mathrm{eV}$

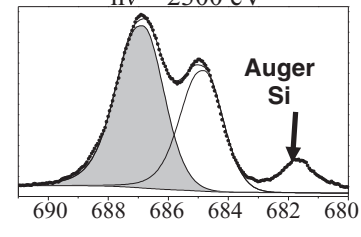

hv $=6900 \mathrm{eV}$

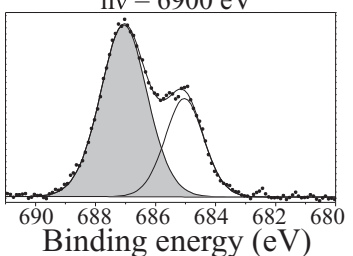

(c) P2p/P1s
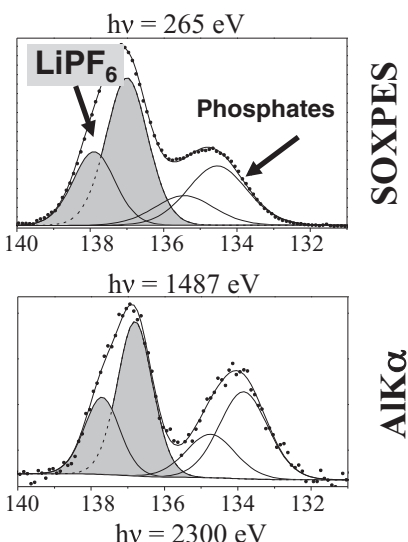

$\frac{7}{2}$

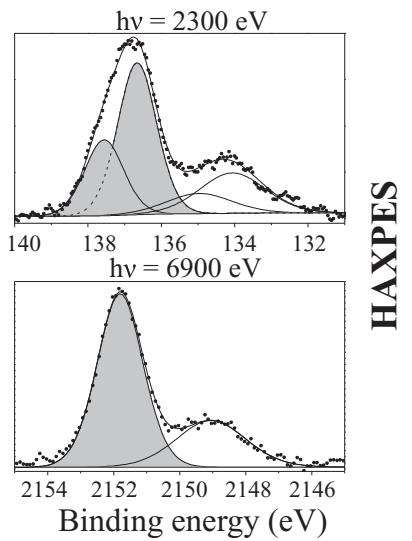

Figure 6. (a) C1s, F1s and P2p/P1s spectra of a Si composite electrode after the $100^{\text {th }}$ discharge as a function of the analysis depth. Adapted from Ref. 37.

Effect of additives on interphase formation.-The SEI layers discussed in the previous section were formed using classical electrolyte compositions, i.e. an electrolyte salt dissolved in organic solvents (EC, DEC, DMC, EMC typically). However, electrolytes in commercial Li-ion batteries are more complex and generally contain many additives. The use of additives can significantly improve the battery performance and additives often result in changes in the SEI chemistry. ${ }^{46}$ PES studies of additives have in general shown the thicknesses of the SEI to increase and the formation of $\mathrm{LiF}$ is in general lower than for non-additive electrolytes. $^{47}$

PES has been used to track the changes in SEI chemistry and to suggest degradation mechanisms. The negative effect of the TPP, a flame retardant (triphenyl phosphate) for high power applications $\left(\mathrm{LiFePO}_{4} /\right.$ graphite cells) required for hybrid electric vehicle was highlighted using, among other techniques, PES. This study showed that, in addition to decreasing the overall conductivity of the battery, the presence of TPP leads to thicker interface layers affecting the performance of the cell in a negative way. ${ }^{48}$ The beneficial use of Glutaric Anhydride (GA) on $\mathrm{LiNi}_{0 .} \mathrm{Mn}_{16} \mathrm{O}_{4} / \mathrm{Li}_{4} \mathrm{Ti}_{5} \mathrm{O}_{12}$ cells was also well illustrated through PES investigations of the SEI and SPI. In the presence of GA additives, thicker interfacial layer were obtained however exhibiting less resistivity than the layers without additives due to a better ionic conductivity. It was shown by PES that the degradation products of GA behave like a polymer electrolyte interface reducing significantly the capacity fading during cycling. ${ }^{49}$

VC (vinylene carbonate) and FEC (fluoroethylene carbonate) are probably the most frequently used additives in electrolytes and generally form a smoother and more stable SEI layer even at elevated temperatures. Investigations suggest the formation of a polymeric structure resulting from the VC or FEC degradation enhancing the overall coverage of the negative electrode by the SEI. The effect of VC was investigated by in-house PES on $\mathrm{LiCoO}_{2} / \mathrm{C}, \mathrm{LiCoO}_{2} / \mathrm{Li}_{4} \mathrm{Ti}_{5} \mathrm{O}_{12}$, $\mathrm{LiFePO}_{4} /$ graphite, and graphite/Li systems and evidence was found that separate mechanisms occur at the negative electrode and at the positive electrode, although the same VC polymer is deposited at the surface of both electrodes, resulting from a radical polymerization process (see Figure 7). ${ }^{50,51}$ A similar degradation route was observed on silicon based electrodes and a thick organic layer was reported. However, the sampling depth of the PES did not allow the study of

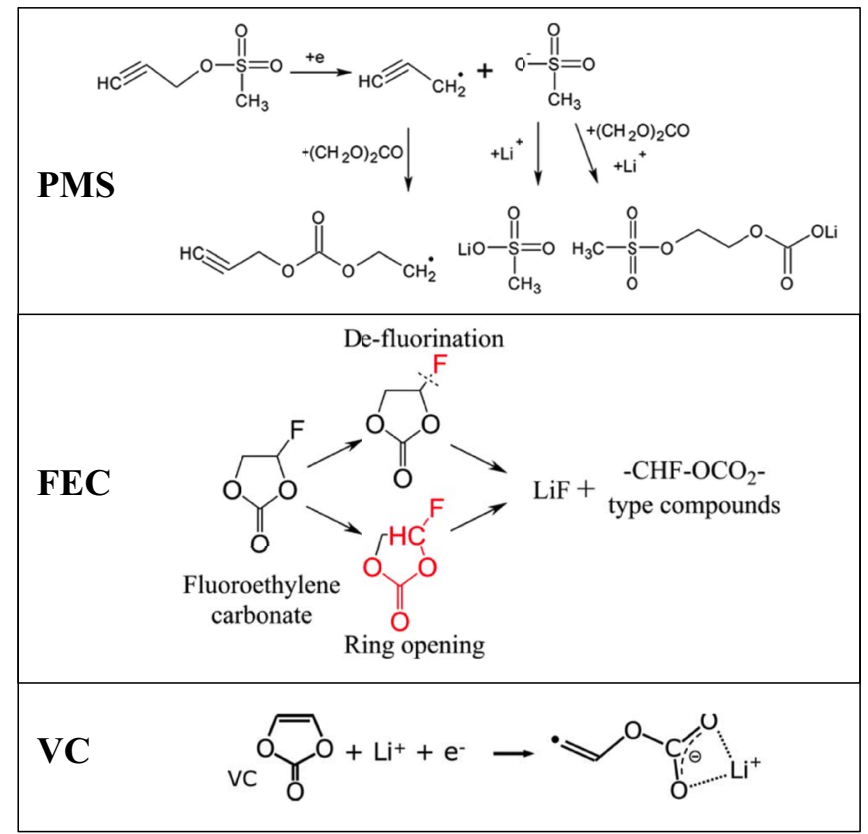

Figure 7. Proposed degradation machanisms of PMS, FEC and VC. 
the $\mathrm{Si} 2 \mathrm{p}$ and it is hence difficult to know if $\mathrm{VC}$ really protects the electrode from side reaction such as e.g. the formation of $\mathrm{SiO}_{\mathrm{x}} \mathrm{F}_{\mathrm{y}}{ }^{52}$

A recent study on silicon electrodes with a combined use of SOXPES and HAXPES indicated a degradation mechanisms of FEC. ${ }^{53}$ The authors show that FEC is degraded prior to the classical solvents due to its higher reduction potential, an initial SEI is formed and will limit both the reduction of EC/DEC and the degradation of the salt $\mathrm{LiPF}_{6}$. A defluorination followed by a ring-opening are the two most probable degradation routes for FEC as illustrated in Figure 7. Using a similar methodology, the positive effect of PMS (propargyl methanesulfonate), a film forming additive, on the SEI and SPI of $\mathrm{LiFePO}_{4} /$ graphite cells was investigated and related to the battery performance. ${ }^{54}$ Figure 7 shows proposed degradation mechanisms of some of the additives mentioned in this section based on PES and theoretical calculations.

Properties of battery electrode materials. - So far, most battery PES studies have focused on the understanding of the SEI. However, PES can also be used to investigate the electrode material itself and follow its evolution during cycling. The method is here a versatile complement to the more common characterization techniques such as XRD, IR or Raman spectroscopy. PES allows for characterization of the surface/interface/bulk depth range of the electrode and the technique can therefore contribute in a unique way to the understanding of the chemical/electrical energy conversion process. In terms of properties, PES can be used to investigate the role of material stoichiometry, oxidation state, impurities etc.. It can also be used to differentiate between electrode surface and bulk as well as to investigate the electrode material buried under a thick SEI.

In a comparison between the negative and positive electrode materials the thickness of the SEI compared to the SPI make studies on the negative materials more complex while reasonable investigations on positive materials can be obtained using an in-house PES. Therefore we will in the first part of this section briefly introduce the use of PES for studies of electrode materials by an in-house investigation of a positive material (3.2.1). In the second part (3.2.2) we will describe the more thorough synchrotron based investigations on the negative electrode materials using combinations of SOXPES and HAXPES by examples from the three main families: insertion/intercalation materials, alloying materials and conversion materials.

Positive electrode materials.-A wide variety of insertion/ intercalation materials have been proposed in the literature and most of them are based on the activity of a transition metal redox couple $\mathrm{M}^{\mathrm{n}+} / \mathrm{M}^{\mathrm{n}+1}$ (with $\mathrm{M}=\mathrm{Co}, \mathrm{Ni}, \mathrm{Mn}, \mathrm{Fe}$, etc). Among the most successful materials $\mathrm{LiCoO}_{2}$ with its layered structure is the most common cathode material in commercial Li-ion batteries. ${ }^{55}$ The high cost of cobalt, its toxicity, and its instability at high potentials pushed researchers to look for alternatives and the solution came in the early 2000's in terms of mixed transition metal oxides. This has led to the development of $\mathrm{LiNi}_{\mathrm{x}} \mathrm{Co}_{\mathrm{y}} \mathrm{Mn}_{\mathrm{z}} \mathrm{O}_{2}$ as battery materials for commercial use showing improved electrical conductivity and a rather stable structure. ${ }^{56}$ We can also mention the use of spinel structure $\mathrm{LiM}_{2} \mathrm{O}_{4}$ and polyanion-based positive electrode materials which are probably the most investigated materials currently, for example $\mathrm{LiFePO}_{4} \cdot{ }^{57}$

In-house PES has been performed to characterize pristine electrodes and determine the active/inactive redox couple in $\mathrm{LiCr}_{0.2} \mathrm{Ni}_{0.4} \mathrm{Mn}_{1.4} \mathrm{O}_{4},{ }^{58}$ to compare $\mathrm{LiFe}_{0.33} \mathrm{Mn}_{0.67} \mathrm{PO}_{4}$ and $\mathrm{LiFePO}_{4},{ }^{59}$ or to evaluate the effect of a coating $\left(\mathrm{ZnO}, \mathrm{Al}_{2} \mathrm{O}_{3}\right.$ or $\mathrm{ZrO}_{2}$ on $\left.\mathrm{LiMn}_{1.5} \mathrm{Ni}_{0.5} \mathrm{O}_{4}\right){ }^{60}$ As an example, Figure 8 shows the evolution of the $\mathrm{Fe} 2 \mathrm{p}$ spectra of a $\mathrm{LiFePO}_{4}$ electrode where the activity of the $\mathrm{Fe}^{2+} / \mathrm{Fe}^{3+}$ redox couple can be clearly observed and correlated to the degree of lithiation. ${ }^{61}$

Most of the positive electrodes contain fluorine (from the electrolyte and/or PVDF binder) and the fluorine KLL Auger lines appear at the same position as Ni2p excited with $\mathrm{AlK} \alpha$, which will significantly disturb the overall signal. Here, the use of synchrotron radiation constitutes a major advantage since by simply tuning the photon en-

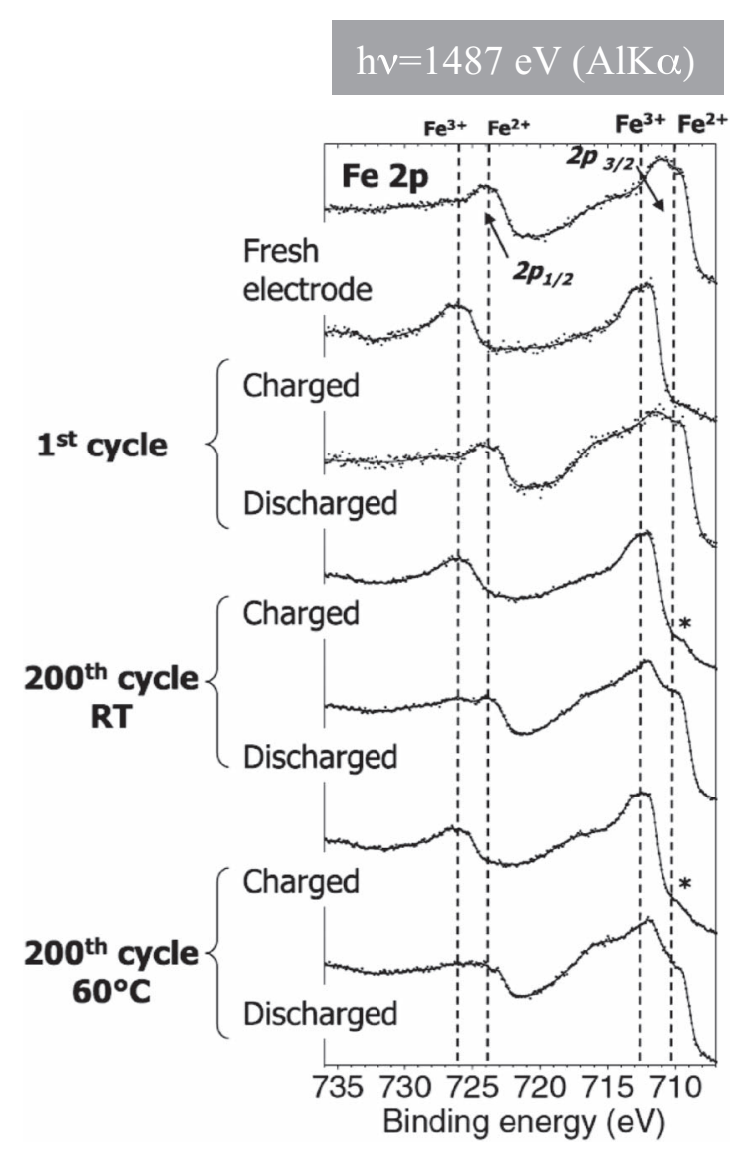

Figure 8. Fe $2 \mathrm{p}$ spectra of the charged and discharged $\mathrm{LiFePO}_{4}$ electrodes upon the 1 st and the 200 th cycle at room temperature and at $60^{\circ} \mathrm{C}$. From Ref. 61.

ergy, the Auger and photoelectron peaks can be separated such that a clear Ni2p signal can be obtained.

Negative electrode materials._Insertion/Intercalation materials.Despite the large number of PES studies reported on graphite electrode materials, the investigation of the mechanism of the direct lithiation/delithiation remains a difficult challenge. Most investigations mainly rely on the C1s spectra and as seen in the spectra presented above, the SEI contains a substantial amount of carbonaceous species making the graphite substrate signal difficult to resolve. However, the use of HAXPES provides improved possibilities to separate the signals from the substrate materials. In particular, it has been shown that the Li signal from the substrate can be observed at an increased probe depth. ${ }^{62}$ These findings are presented in Figure 9. The C1s and Li1s core level peaks (in black) of $\mathrm{Li}_{\mathrm{x}} \mathrm{C}$ are clearly distinguishable from the SEI components (in yellow). From these results it was possible to make an estimate of the amount of lithium present in the carbon electrode surface region. The relation between the amount of lithium reduced at the surface and the carbon active material was found to be close to one-to-one in this investigation. This may indicate the deposition of metallic lithium at the interface or the formation of a lithium enriched carbon outer layer in a more disordered form, surrounding the $\mathrm{LiC}_{6}$.

The study of electrode materials other than graphite may allow more straightforward interpretations to be made of PES results pertaining to ion insertion. For instance, it has been shown that electrochemical lithiation of nanostructured anatase $\mathrm{TiO}_{2}$ forms $\mathrm{Li}_{\mathrm{x}} \mathrm{TiO}_{2}$ where the titanium is reduced from $\mathrm{Ti}^{4+}$ to $\mathrm{Ti}^{3+}$. Upon $\mathrm{Li}$ insertion in anatase $\mathrm{TiO}_{2}$ a phase separation into a $\mathrm{Li}$-poor and a Li-rich phase occurs. ${ }^{63-65}$ The Li-poor phase is crystallographically very similar to the original anatase structure, whereas the Li-rich phase has a different geometric structure. The transformation from anatase to the Li-rich 
HAXPES

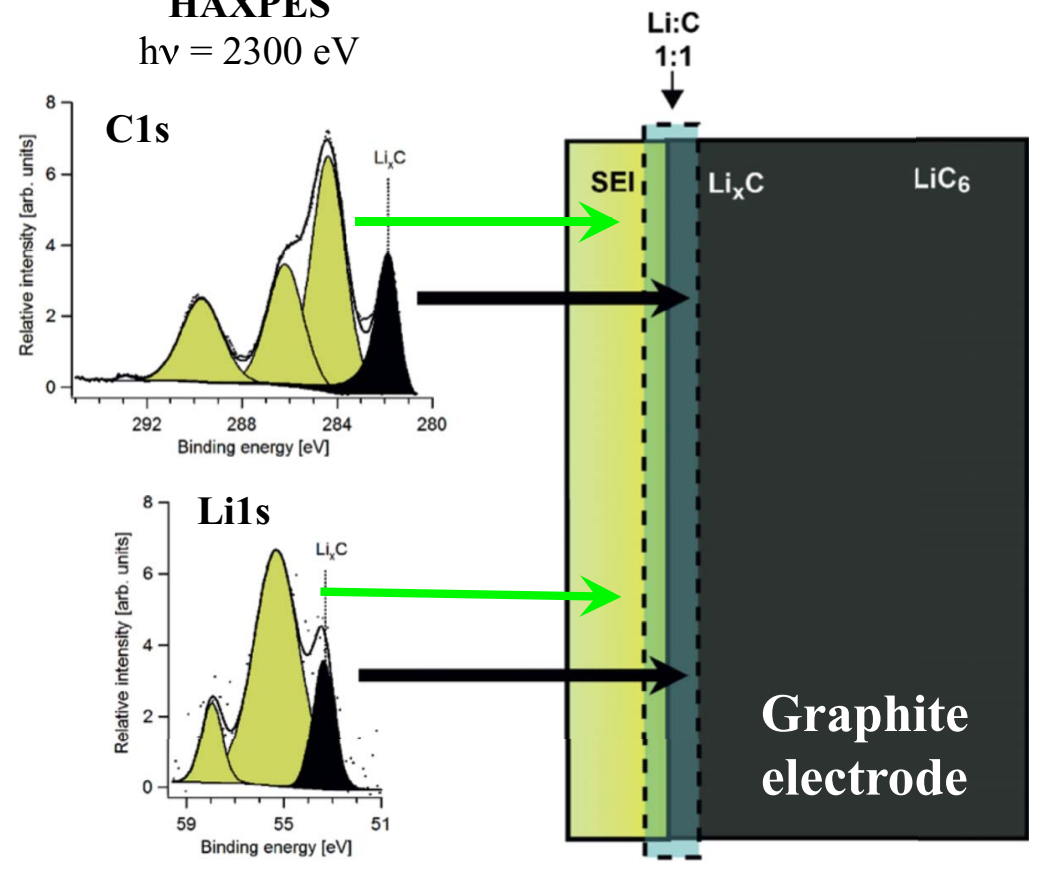

Figure 9. C1s and Li1s HAXPES spectra $(\mathrm{h} v=2300 \mathrm{eV})$ of a lithiated carbon electrodes showing a 1:1 ratio of graphite carbon atoms and intercalated $\mathrm{Li}$ atoms, implicating an excess of lithium compared to carbon with $\mathrm{LiC}_{6}$ composition. Adapted from Ref. 62 . phase is described as an orthorombic distortion of the atomic positions and the $x$ value is estimated to be 0.5 . $^{66}$ The Li-rich phase is therefore commonly denoted lithium titanate of formal stoichiometry $\mathrm{Li}_{0.5} \mathrm{TiO}_{2}$. As can be seen from the Ti $2 p$ PES spectra, see Figure 10 (right), a new peak appears upon lithium insertion attributed to $\mathrm{Ti}^{3+}$ states. Although these measurements were performed with very high surface sensitivity SOXPES, a good match between the $\mathrm{Ti}^{4+} / \mathrm{Ti}^{3+}$ ratio and the charge electrochemically stored was found, which indicates that the insertion process is vertically largely homogeneous. ${ }^{67}$

Model studies on the electrochemical lithiation process have also been performed by the evaporation of metallic lithium onto an electrode material under UHV conditions. ${ }^{68}$ The feasibility of lithium insertion into a nanostructured anatase $\mathrm{TiO}_{2}$ film under UHV conditions was demonstrated by employing $\mathrm{PES}^{69}$ (see Figure 10 (left)). A comparison of the resulting spectra obtained in the ultraclean environment of UHV and those obtained for samples prepared with electrochemical insertion (Figure 10 (right)) thus allows distinguishing the effects associated with the electrode/electrolyte interaction. A clear difference between the two insertion methods is observed in the latter spectra. The O1s spectra for the electrochemical insertion process show the growth of a high binding energy component that, for the highest amounts of lithium, dominates the spectrum. In line with the discussions above, this overlayer component stems from the presence of the SEI. An estimate of the charge transfer between lithium and titanium was performed using the Ti $3 d$ bandgap peak compared to the $\mathrm{Ti}^{3+}$ contribution of the corresponding Ti $3 p$ peak. The Ti $3 d$ intensity was found to increase linearly with $x$ up to a value of about 0.35 . A relatively constant electron transfer ratio was found in this interval with a value of $0.85 e \pm 0.10 e$ transferred to Ti $3 \mathrm{~d}$ bandgap states in good agreement with theoretical calculations.

Materials with a more complex chemistry or containing multiple transition metals have been investigated, such as for example titanium oxyphosphate materials. ${ }^{70}$ The lithium insertion can take place at potentials above that for a substantial SEI formation, and these materials show high rate capability as well as good and stable specific capacity. The stability of the phosphate group also renders these materials rather safe electrode materials. In a recent HAXPES study on $\mathrm{Ni}_{0.5} \mathrm{TiOPO}_{4}$, cells cycled between 3 and $0.5 \mathrm{~V}$ were investigated and changes in oxidation states of both $\mathrm{Ni}$ and Ti could clearly be followed as a function of lithiation in the Ni $2 p$ and $\mathrm{Ti} 2 \mathrm{p}$ core level spectra, see Figure 11. The insertion of lithium causes the $\mathrm{Ni}$ atoms to change from a $\mathrm{Ni}^{2+}$ state to $\mathrm{Ni}^{0}$ state, while $\mathrm{Ti}$ changes from $\mathrm{Ti}^{4+}$ to a mixture of $\mathrm{Ti}^{4+}$, $\mathrm{Ti}^{3+}$ and $\mathrm{Ti}^{2+}$ in the relative amounts of 11:10:3 after insertion of 3.5 charge per formula unit. Coupling this to the plateau in the cycling curve, it could be deduced that changes in both elements occur during both plateaus, but that the first part is dominated by the change in $\mathrm{Ti}$ and the second part is dominated by the change in Ni. It could also be determined that some, but not all, of the loss in battery capacity is related to the non-reversible $\mathrm{Ni}^{0}$ state formed during the $\mathrm{Li}$ insertion.

Alloying materials. - As mentioned earlier, silicon is a serious candidate as the next possible negative electrode material in commercial Li-ion batteries replacing graphite. Si alloys with lithium below $0.8 \mathrm{~V} \mathrm{vs.} \mathrm{Li}^{+} / \mathrm{Li}$ and passes during the electrochemical process through a number of different $\mathrm{Li}_{\mathrm{x}} \mathrm{Si}$ phases up to the fully lithiated $\mathrm{Li}_{15} \mathrm{Si}_{4}$ at room temperature. By combining SOXPES and HAXPES investigations, a depth profiling of the outermost surface down into the bulk of the silicon electrode was performed and has provided important information about the role of the native silicon oxide during the cycling of the battery. ${ }^{21,37}$

Figure 12a shows the Si2p spectra of the pristine electrode as a function of the photon energy used. At low photon energies, the $\mathrm{SiO}_{2}$ peak at $103.5 \mathrm{eV}$ is the main component whereas bulk Si becomes the main component at higher energies in accordance with a silicon surface oxidized under ambient conditions. Figure $12 b$ shows the $\mathrm{Si} 2 \mathrm{p}$ spectra of the Si composite electrode cycled 100 times in $\mathrm{LiPF}_{6} 1 \mathrm{M}$, EC:DEC (2:1). The Si2p spectra from the outermost surface show that a fluorinated $\mathrm{SiO}_{\mathrm{x}} \mathrm{F}_{\mathrm{y}}$ feature appears at $\sim 106.5 \mathrm{eV}$ after a long cycling of the battery. The spectra also show that $\mathrm{SiO}_{2}$ is present mainly in the outer surface layers and that a lithiated silicon oxide $\left(\mathrm{Li}_{4} \mathrm{SiO}_{4}\right)$ material appears irreversibly deeper in the material. This latter compound is formed already after the first discharge of the cell. The total surface layer including the silicon-based compounds as well as the classical SEI (organic and inorganic estimated to be below $5 \mathrm{~nm}$ in this present case) is so thick that the signal from the lithiated silicon appears only when a photon energy of $1486.6 \mathrm{eV}$ is used. The results imply that the surface oxide reacts with the anion in $\mathrm{LiPF}_{6}$ or with $\mathrm{HF}$ resulting from the hydrolysis of $\mathrm{PF}_{6}{ }^{-}$.

Figure 13 presents a summary of the conclusions concerning the SEI resulting from different electrochemical and chemical treatments of the silicon electrode. The electrode has both been cycled and stored in electrolyte. Together with the spectra in Figure 13a, the schematic representation in Figure 13b shows that the storage also leads to 

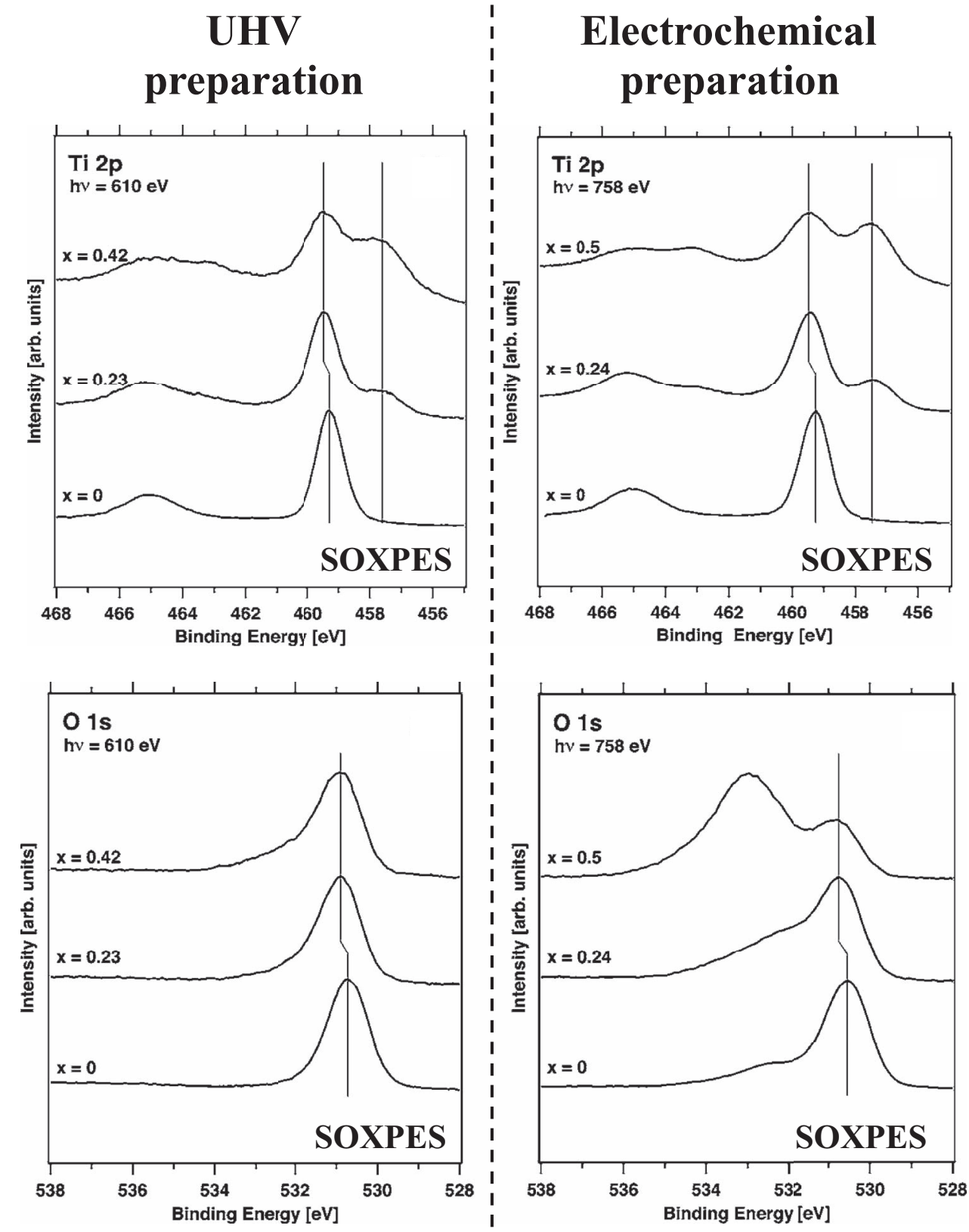

Figure 10. Ti $2 \mathrm{p}$ and $\mathrm{O} 1 \mathrm{~s}$ core level photoemission spectra for increasing amounts of Li inserted by (left) UHV evaporation and (right) electrochemistry. Adapted from Ref. 69.

reactions between the $\mathrm{PF}_{6}{ }^{-}$anion and the surface silicon oxide. If the SEI is formed before storage it can slow down the reaction with the electrolyte salt during storage.

By replacing $\mathrm{LiPF}_{6}$ with LiFSI, a salt more stable toward hydrolysis, it was shown that the formation of the fluorinated species $\mathrm{SiO}_{\mathrm{x}} \mathrm{F}_{\mathrm{y}}$ was prevented and that the battery performance was significantly improved. Finally, the higher surface sensitivity provided by SOXPES allowed the degradation of this salt to be followed and a degradation mechanism to be proposed supported also by calculation. With LiFSI, a faster degradation occurs at the beginning of the first discharge and that the reduction products act as a passivation layer which prevents further salt degradation thus preserving the electrochemical performances of the battery. ${ }^{71}$

Figure 14 shows another example of material alloying with lithium, the intermetallic compound $\mathrm{MnSn}_{2}$. It was found that tin and manganese oxides are present at the extreme surface of the particles but contrary to the silicon case, these two oxides do not react with the electrolyte by simple contact. The PES investigation coupled with
Mössbauer analysis showed that a reduction at the surface of tin oxide $\mathrm{SnO}_{2}$ occurs resulting in the formation of $\mathrm{Li}_{2} \mathrm{O}$ until the end of the discharge and that $\mathrm{Li}_{2} \mathrm{O}$ disappears upon charging. ${ }^{72}$ Lithium insertion into $\mathrm{MnSn}_{2}$ during the discharge leads to the formation of a nanocomposite consisting of the $\mathrm{Li}-\mathrm{Sn}$ alloy $\mathrm{Li}_{7} \mathrm{Sn}_{2}$ and of $\mathrm{Mn}$ nanoparticles, which are immediately oxidized at their surface. During the discharge, the partial delithiation of $\mathrm{Li}_{7} \mathrm{Sn}_{2}$ and the formation of $\mathrm{Li}$-poor $\mathrm{Li}-\mathrm{Sn}$ and/or Li-Mn-Sn phases occurs without retrieval of $\mathrm{MnSn}_{2}$. During the second charge plateau, further de-lithiation leads to the formation of magnetic $\mathrm{MnSn}_{2}$ particles.

Conversion materials. - One family of materials used as negative electrode is referred to as conversion materials and contains a transition metal coupled with an anion. Since 2000, most of the attention has been devoted to transition metal oxides (TMO) since they usually present a very high capacity retention and high theoretical capacities. $^{73-75}$ The general reaction is described by:

$$
\mathrm{M}_{\mathrm{x}} \mathrm{O}_{\mathrm{y}}+2 \mathrm{yLi}^{+}+2 \mathrm{ye}^{-} \leftrightarrow \mathrm{yLi}_{2} \mathrm{O}+\mathrm{xM}
$$



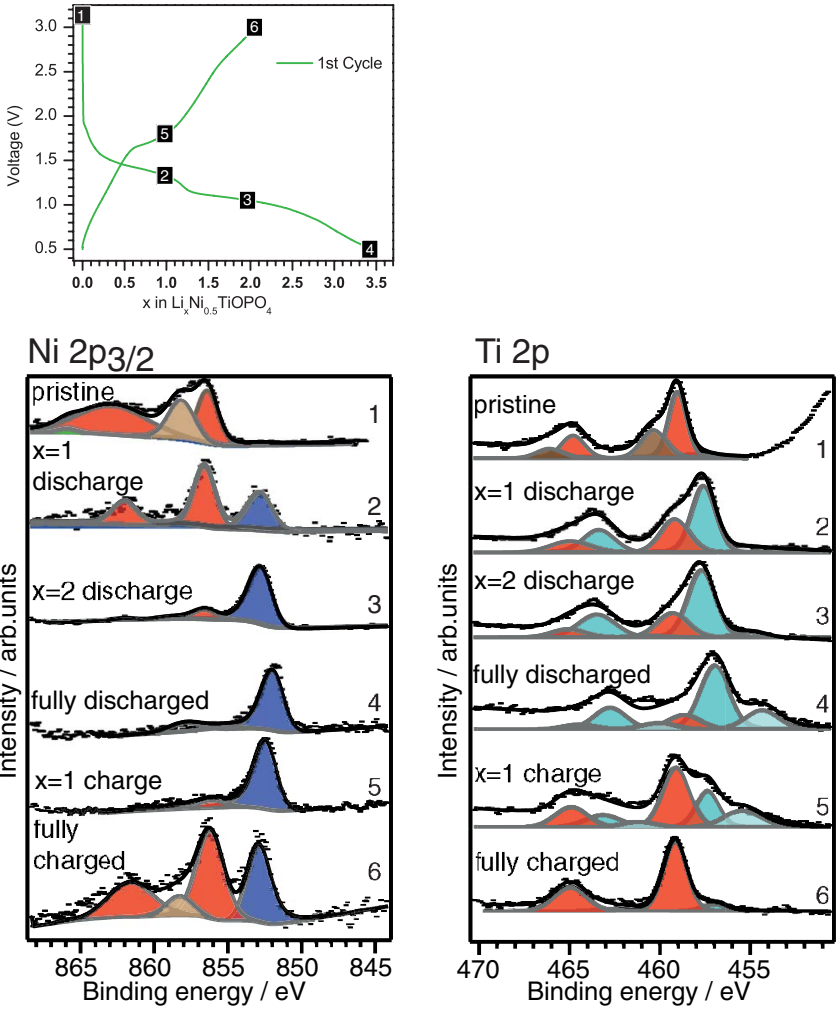

Figure 11. The galvanostatic lithiation/delitiation voltage profile of $\mathrm{Ni}_{0.5} \mathrm{TiOPO}_{4} / \mathrm{C}$ cycled with a voltage window from 3.0 to $0.5 \mathrm{~V}$ at $\mathrm{C} / 20$ rate (top). HAXPES Ni2p (bottom, left) and Ti2p (bottom, right) results from $\mathrm{Ni}_{0.5} \mathrm{TiOPO}_{4}$ electrode material cycled versus lithium metal and stopped at nine different degrees of lithiation. The data was obtained using a photon energy of $2300 \mathrm{eV}$. Adapted from Ref. 70. (a) Pristine electrode

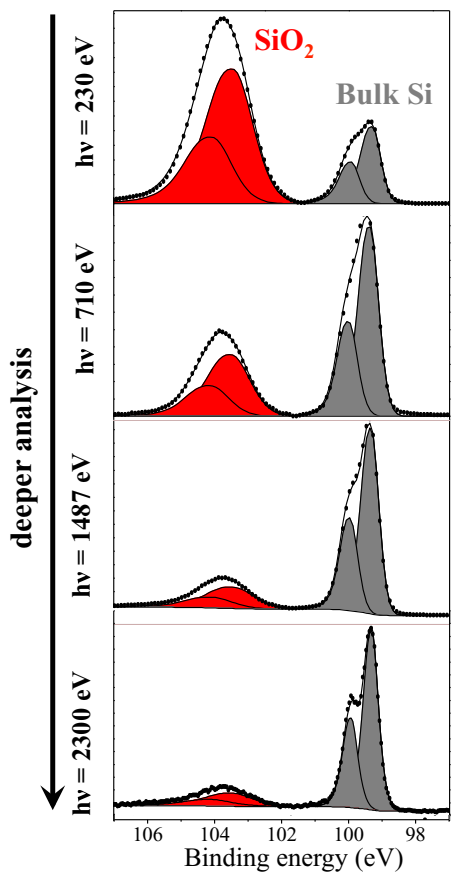

(b) After 100 cycles

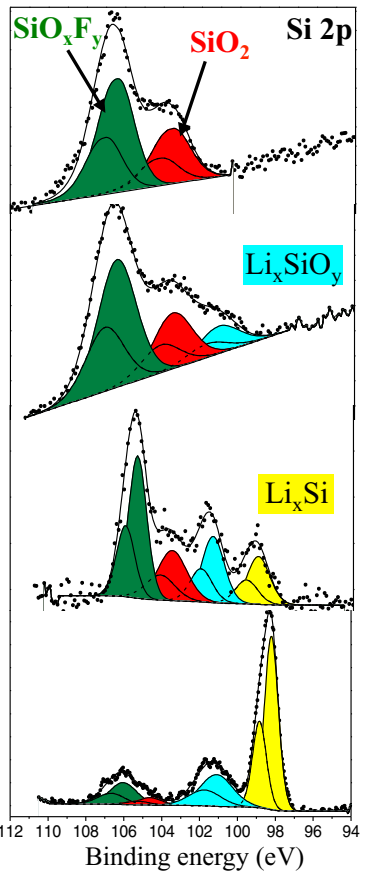

Figure 12. Evolution of the Si2p core level peak of Si-based pristine electrode (a) and after 100 cycles (b) presented as function of photon energy used, i.e. the analysis depth. Adapted from Refs. 21 and 37.

Cobalt oxides, such as $\mathrm{CoO}$ are among the most explored TMOs and more recently iron oxides are also identified as good candidates. The hematite $\mathrm{Fe}_{2} \mathrm{O}_{3}$ or the magnetite $\mathrm{Fe}_{3} \mathrm{O}_{4}$ have both the advantages of being highly abundant and non-toxic and they display an interesting theoretical capacity (1007 and $926 \mathrm{mAh} . \mathrm{g}^{-1}$, respectively). The

(a)

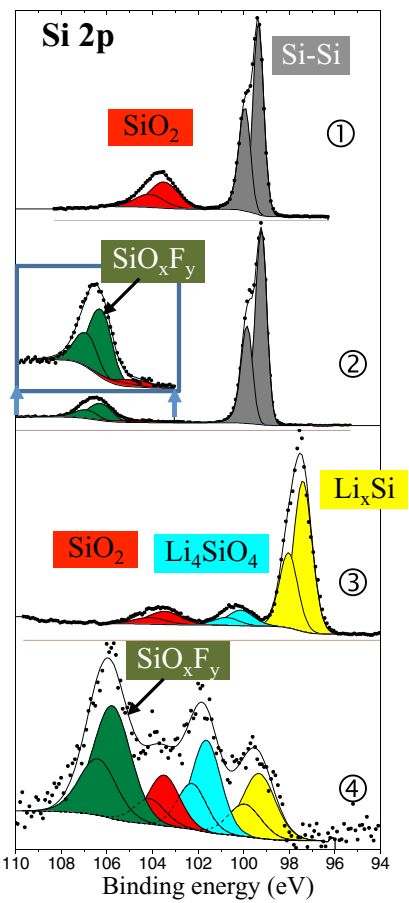

(b)
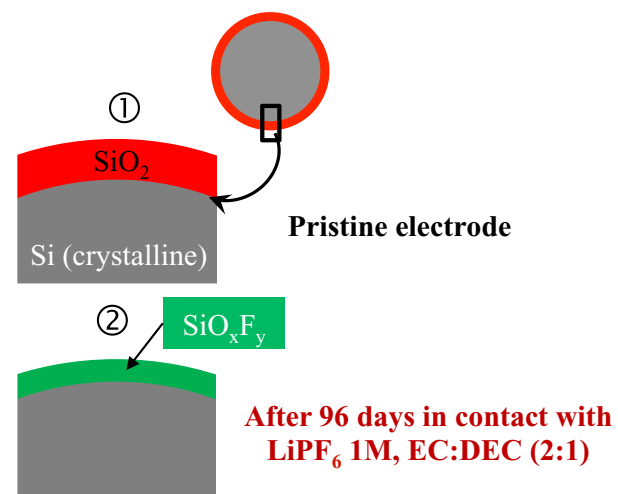

(3)

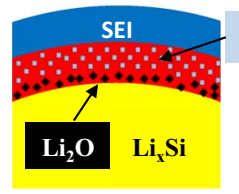

$\mathrm{Li}_{4} \mathrm{SiO}_{4}$

After 1st discharge until $500 \mathrm{mAh} / \mathrm{g}$ of $\mathrm{Si}$ (then stored for 196 days)

(4)

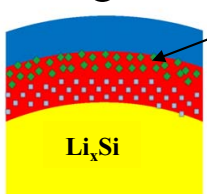

\section{$\mathrm{SiO}_{\mathrm{x}} \mathrm{F}$}

After 100 discharges

$[0.9-0.12 \mathrm{~V}]$ (then stored for 41 days)
Figure 13. (a) Si $2 p$ spectra (in-house PES, $1487 \mathrm{eV}$ ) (1) of the $\mathrm{Si} / \mathrm{C} / \mathrm{CMC}$ pristine electrode, (2) of a pristine electrode in contact 96 days with the electrolyte, (3) after a first discharge until $500 \mathrm{mAh} / \mathrm{g}$ of $\mathrm{Si},(4)$ after the 100th discharge at $0.12 \mathrm{~V}$ (with precycling) (to the left). (b) Schematic view of the compounds formed on the silicon particle surfaces during cycling and/or during storage with the electrolyte. Adapted from Ref. 37. 
(a) Pristine electrode

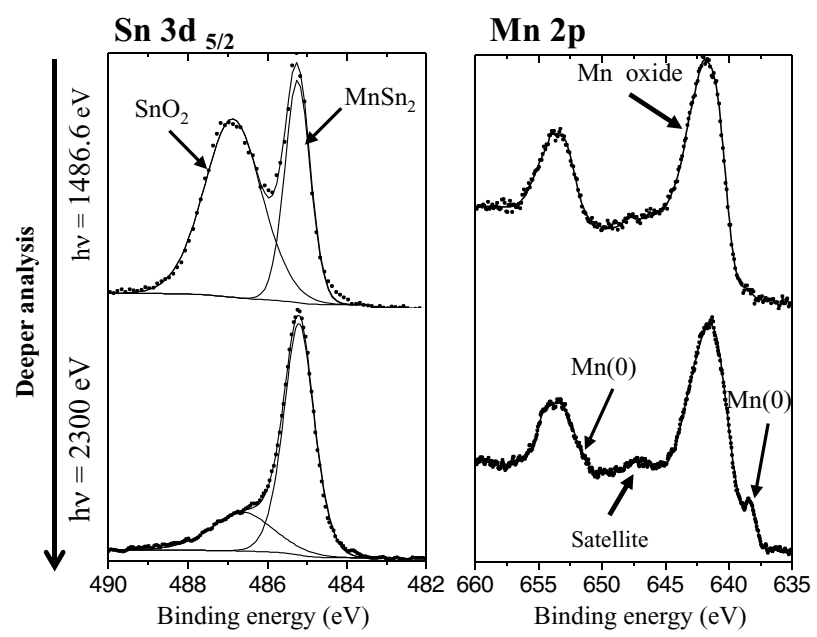

(b) Sn3d: first cycle

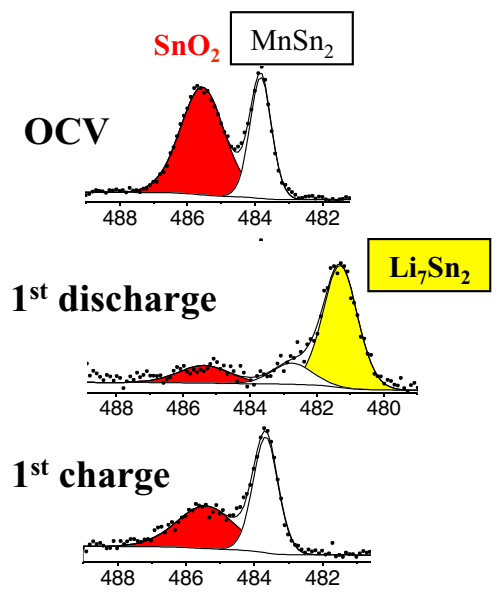

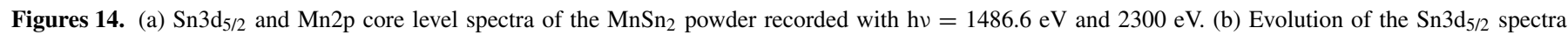
during the first cycle $(\mathrm{h} v=1486.6 \mathrm{eV})$. Adapted from Ref. 72 .

massive structural reorganization and the electrochemical reactions occurring make conversion materials very attractive for PES studies. The conversion reactions can be studied by following the evolution of one of the transition metal core level peaks and the oxygen core level peaks. Figure 15 illustrates this point with the example of $\mathrm{Fe}_{2} \mathrm{O}_{3}$ and $\mathrm{CoO}$ and their corresponding reaction with lithium: ${ }^{38,76}$

$$
\begin{gathered}
\mathrm{Fe}_{2} \mathrm{O}_{3}+6 \mathrm{Li} \leftrightarrow 2 \mathrm{Fe}+3 \mathrm{Li}_{2} \mathrm{O} \\
\mathrm{CoO}+2 \mathrm{Li} \leftrightarrow \mathrm{Co}+\mathrm{Li}_{2} \mathrm{O}
\end{gathered}
$$

For $\mathrm{Fe}_{2} \mathrm{O}_{3}$, we can in a first step observe an intermediate phase $\mathrm{Li}_{\mathrm{x}} \mathrm{Fe}_{2} \mathrm{O}_{3}$ both in the $\mathrm{Fe} 3 \mathrm{p}$ spectra and $\mathrm{O} 1 \mathrm{~s}$ spectra. When we go further in discharge, the conversion reaction occurs and metallic iron and $\mathrm{Li}_{2} \mathrm{O}$ are formed and detected by PES. We can clearly see that this reaction is reversible as $\mathrm{Fe}^{0}$ and lithium oxide disappear during the following charge. The same behavior is observed in Figure 15 showing the evolution of the Co2p core level peak during the first electrochemical cycle. The cobalt oxide is completely converted into metallic Co during the discharge and regenerated during the charge.

We have shown with the above examples that, in addition to information on the SEI, photoelectron spectroscopy can also provide important information on the electrochemical reactions occurring within the electrode materials or at its extreme surface which cannot easily be detected by other techniques. In addition, PES offers a direct view of most of the reactions occurring for negative electrodes materials i.e. insertion, alloying or conversion and the reversibility of these reactions.

The above discussion was related to Li-ion batteries materials. Emerging battery technologies such as Li-air, $\mathrm{Na}$-ion, $\mathrm{Li}-\mathrm{S}$ or $\mathrm{Mg}$ battery are currently investigated and will also require a better understanding of the reactions occurring at the electrode/electrolyte interface. Synchrotron radiation based PES studies have recently been performed on the Li-air battery ${ }^{77-79}$ and a first detailed investigation using SOXPES of the SEI formed in a Na-ion battery compared that in a Li-ion battery has recently been published by our group. ${ }^{38}$ SEI studies of Na-ion batteries using in-house PES has become more common $^{80-82}$ and an investigation using HAXPES on hard carbon was recently reported. ${ }^{83}$

\section{Future Prospects of PES Methods for Battery Research}

Photoelectron spectroscopy is undergoing continuous development and for battery research, efforts are now being made to develop experimental methods toward more realistic in-operando conditions and to perform the electrochemistry in closer proximity to the subsequent surface analysis. This is also intended to allow for easier interpretation of cycling data on the same sample. An early version of such an arrangement was used by us in intercalation studies of electrochromic effects in tungsten oxide electrodes. ${ }^{84}$ Substantial progress has been made during recent years in creating more realistic environments for samples being analyzed under vacuum conditions in particular for the study of high vapor pressure samples, such as catalytic surfaces or cycled battery electrodes. Already in the early phases of photoelectron spectroscopy such techniques were developed for studies of gases and liquids based on specially designed pumping arrangements of the sample region. ${ }^{85}$ More recently, however, these techniques have advanced considerably due to combined utilization of synchrotron radiation and electron optics. ${ }^{86-89}$

The principle of the new technique (so-called Ambient Pressure Photoelectron Spectroscopy (APPES)) is sketched in Figure 16. In these instruments a series of slits is introduced prior to the analyzer entrance associated with heavy intermediate differential pumping to reduce a sample vapor pressure load. However, this also means a loss rate of the photoelectrons of the same order of magnitude. By introducing focusing lens systems into the differential pumping stages, as shown in this figure, this loss rate can be largely overcome. Moreover, with high brilliance synchrotron radiation excitation, aperture sizes can be substantially reduced, which further reduces the gas load along the electron paths. The overall result of this design principle is that pressure gradients of eight to nine orders of magnitude can be maintained between the sample region and the spectrometer while still sufficient intensities of photoelectrons will be transmitted. For the study of battery electrodes, this allows for the presence of electrolyte during the measurements, simulating more closely the real interfacial conditions of the battery electrode.

Recently, pilot experiments were performed in a lab-based APPES setup exploring the possibilities to directly access the solid/liquid interface of silicon-based electrodes. ${ }^{90}$ Figure 17 shows the principle of the experiment. The sample silicon electrodes were introduced via the load-lock chamber under nitrogen atmosphere. Inside the chamber, a drop of electrolyte (in this case $1 \mathrm{M} \mathrm{LiClO}_{4}$ in propylene carbonate) was then deposited on the electrode surface. Subsequently, the nitrogen pressures inside the load-lock and the analysis chamber were equilibrated to $2 \mathrm{mbar}$, which is a normal operating pressure for the APPES measurements, and the sample electrode was introduced for analysis. The position of the sample electrode was then carefully 

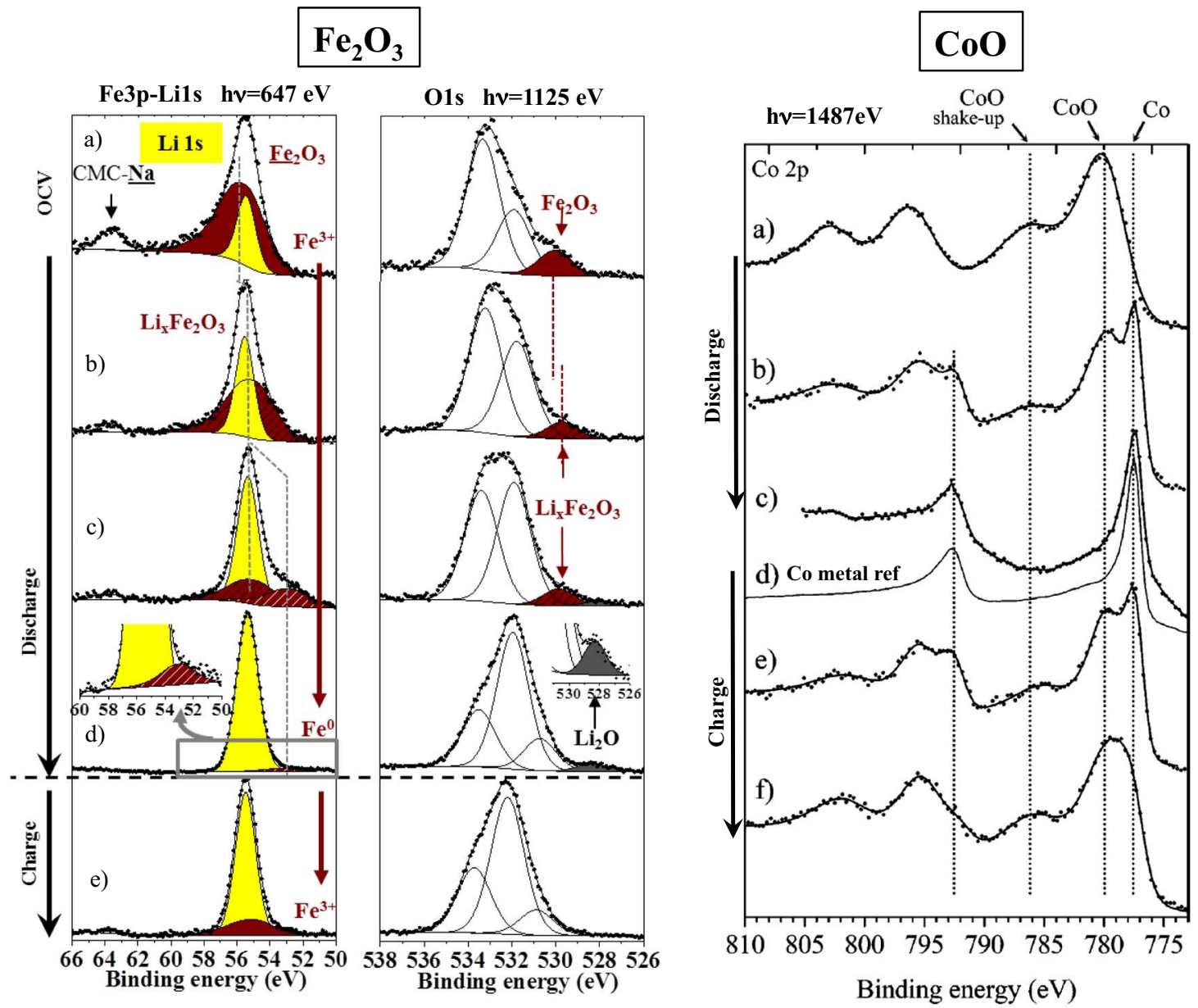

Figure 15. On the left: $\mathrm{Li1s} / \mathrm{Fe} 3 \mathrm{p}$ and $\mathrm{O} 1 \mathrm{~s}$ core level spectra of the $\mathrm{Fe}_{2} \mathrm{O}_{3} / \mathrm{CMC} / \mathrm{CB}$ electrode at different states of charge during the first discharge/ charge cycle $(\mathrm{h} \nu=647 \mathrm{eV}$ and $1125 \mathrm{eV}$ respectively) (a) OCV electrode, (b) discharged at $1.4 \mathrm{~V}$, (c) discharged at $0.9 \mathrm{~V}$, (d) end of discharge (0.05 V), (e) end of charge (2.8 V). On the right: Co $2 \mathrm{p}$ core level spectra of (a) starting $\mathrm{CoO}$ powder, (b) discharged at $\mathrm{x}=1 \mathrm{Li}$, (c) discharged at $0.02 \mathrm{~V}$, (d) metallic cobalt foil as a comparison, (e) charged at $1.8 \mathrm{~V}$, and (f) charged at $3.0 \mathrm{~V}(\mathrm{~h} v=1486.6 \mathrm{eV})$. Adapted from Refs. 38 and 76.

controlled, so that different spots on the electrode could be analyzed having low to fully coverage by the electrolyte drop. The results are shown in Figure 17, showing the Si2p and $\mathrm{C} 1 \mathrm{~s} / \mathrm{Cl} 2 \mathrm{~s}$ spectra. As can be seen, a position of analysis can be achieved, such that both the signals from the substrate and the electrolyte can be simultaneously observed. This is interpreted as a direct observation of the solid/liquid interfacial region within the escape depth of below 50 $\AA$ of the measurement. Due to the presence of the inert gas during the analysis, the electrolyte drop is retained for a sufficiently long time (more than an hour) to allow the spectra of the interface to be recorded.

Further development toward in operandi PES measurements of battery electrodes is presently implemented at the APPES station SPECIES at the synchrotron facility MAX IV in Sweden. A split-up view of the arrangement is shown in Figure 18, designed to allow for standard three-electrode electrochemical experiments. The electrode sample is first in a position for battery cycling via the mounting of the electrode on a rotating wheel placed half way into a cup holding the electrolyte. Subsequenly, the processed electrode is rotated into position for the APPES measurement. The device will allow in situ post-rinsing of exposed surfaces between treatments. The arrangement of Figure 18 implies an entirely novel approach, where the electrochemistry is performed in situ in the high pressure cell of the APPES instrument thus avoiding complex transfer operations and bringing the processes under study in as close proximity as possible to the subsequent analysis.

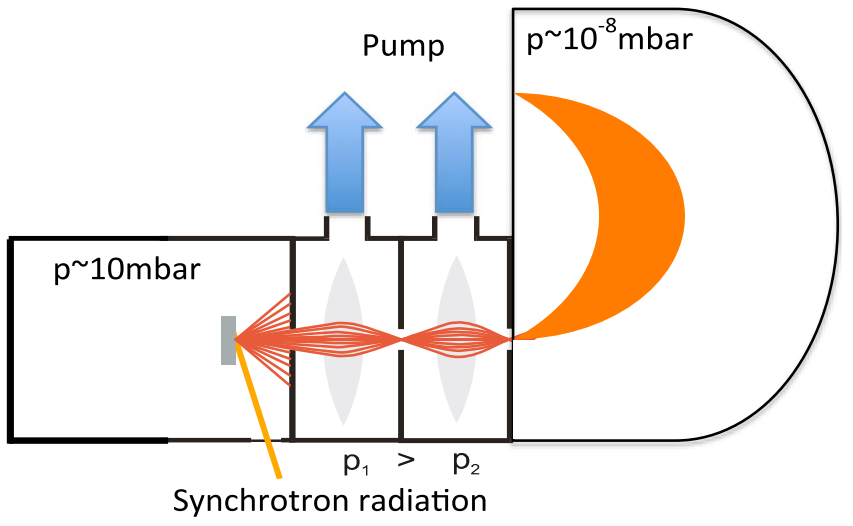

Figure 16. Principle of the experimental setup for studies of ambient pressure substances with photoelectron spectroscopy. The combined use of differential pumping stages and electron lens systems allows for substantially increased sample pressures while retaining photoelectron intensities. The use of this scheme is further advantaged using synchrotron radiation of high brilliance. 


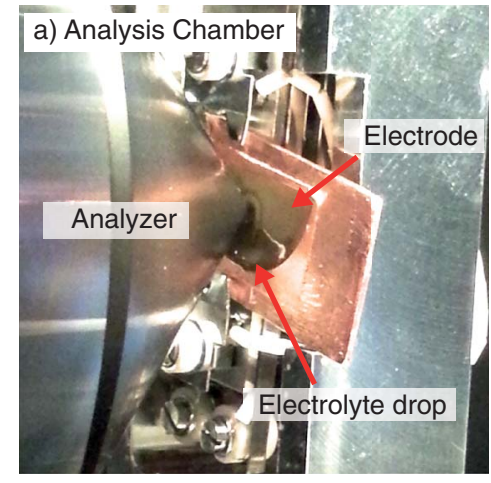

\section{(b) Measurement position}

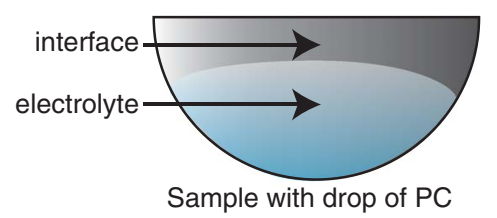

Figure 17. (a) Picture of the sample placed in 2 mbar HPXPS measurement position, where the liquid electrolyte is clearly visible. (b) Approximate beam positions for the individual measurements are indicated in the schematic picture. (c) Si2p and (d) $\mathrm{C} 1 \mathrm{~s} / \mathrm{Cl} 2 \mathrm{~s}$ core level spectra corresponding to the different sample positions shown in (b), i.e. the reference electrode in blue, interface in green, and electrolyte in red. Peak shifts may occur between spectra recorded at different spots depending on local conditions including e.g. interfacial dipoles. The observed spectra provide means of depth profiling the electrode from the electrode material through the interfacial region up to the electrolyte/vacuum interface. Adapted from Ref. 90.
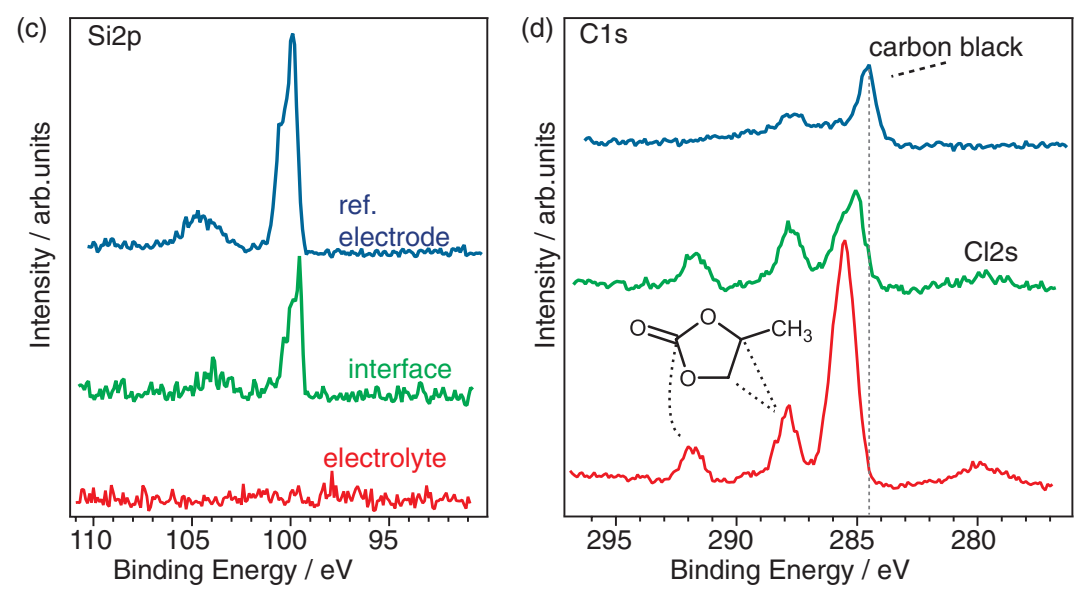

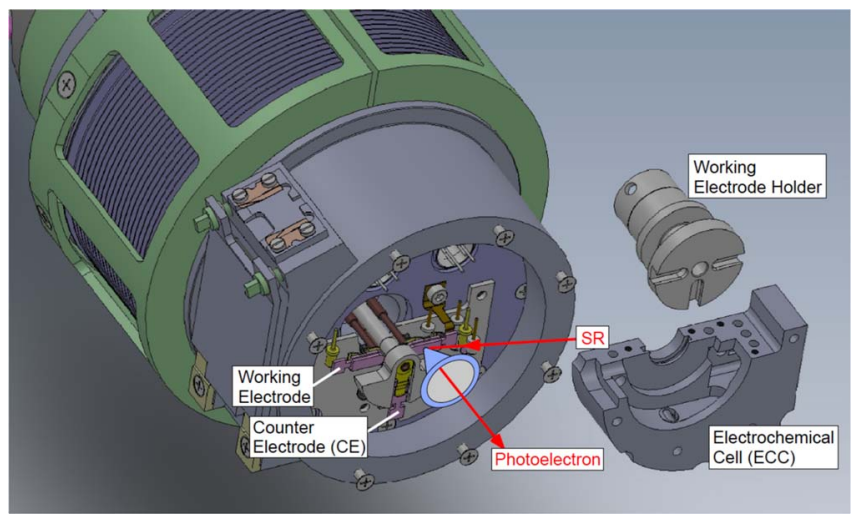

Figure 18. Illustration of the in-situ electrochemical cell designed for APPES.

\section{Acknowledgments}

This work has been supported by the Swedish Research Council (VR 2012-4681), the Swedish Energy Agency and the Wallenberg Foundation. The strategic energy alliance STandUP for Energy is also gratefully acknowledged.

\section{References}

1. T. Nagaura and K. Tozawa, Prog. Batteries Sol. Cells, 9, 209 (1990).

2. J.-M. Tarascon and M. Armand, Nature, 414, 359 (2001).

3. M. Armand and J.-M. Tarascon, Nature, 451, 652 (2008).

4. M. Winter and R. J. Brodd, Chem. Rev., 104, 4245 (2004)

5. M. R. Palacín Chem. Soc. Rev., 38, 2565 (2009).

6. V. Etacheri, R. Marom, R. Elazari, G. Salitra, and D. Aurbach, Energy Environ. Sci. 4, 3243 (2011).

7. M. N. Obrovac and V. L. Chevrier, Chem. Rev., 114, 11444 (2014).

8. L. Croguennec and R. Palacin J. Am. Chem. Soc., 137, 3140 (2015).

9. E. Peled, J. Electrochem. Soc., 126, 2047 (1979).

10. K. Edström, T. Gustafsson, and J. O. Thomas, Electrochim. Acta, 50, 397 (2004).
11. P. Verma, P. Maire, and P. Novák, Electrochim. Acta, 55, 6332 (2010)

12. A. M. Andersson, M. Herstedt, A. G. Bishop, and K. Edström, Electrochim. Acta, 47, 1885 (2002).

13. A. M. Andersson, Doctoral thesis, Uppsala University (2001).

14. M. Herstedt, Doctoral thesis, Uppsala University (2004).

15. K. Xu, Chem. Rev., 104, 4303 (2004).

16. K. Xu, Chem. Rev., 114, 11503 (2014)

17. S. Malmgren, K. Ciosek, R. Lindblad, S. Plogmaker, J. Kühn, H. Rensmo, K. Edström, and M. Hahlin, Electrochim. Acta, 105, 83 (2013).

18. K. Edström, M. Herstedt, and D. P. Abraham, J. Power Sources, 153, 380 (2006).

19. W. Fredriksson, S. Malmgren, T. Gustafsson, M. Gorgoi, and K. Edstroöm, Appl. Surf. Sci. 258, 5790 (2012).

20. S. Malmgren, K. Ciosek, M. Hahlin, T. Gustafsson, M. Gorgoi, H. Rensmo, and K. Edström, Electrochim. Acta, 97, 23 (2013).

21. B. Philippe, R. Dedryvère, J. Allouche, F. Lindgren, M. Gorgoi, H. Rensmo, D. Gonbeau, and K. Edström, Chem. Mater, 24, 1107 (2012).

22. K. Ciosek Högström, Doctoral thesis, Uppsala University (2014)

23. E. Peled, J. Electrochem. Soc., 126, 2047 (1979).

24. A. Zaban and D. Aurbach, J. Power Sources, 54, 289 (1995)

25. D. Aurbach and A. Zaban, J. Electroanal. Chem., 348, 155 (1993).

26. E. Peled, D. Golodnitsky, and G. Ardel, J. Electrochem. Soc., 144, L208 (1997).

27. D. Aurbach, B. Markovsky, I. Weissman, E. Levi, and Y. Ein-Eli, Electrochim. Acta, 45, 67 (1999).

28. D. Aurbach, J. Power Sources, 89, 206 (2000).

29. D. Aurbach, B. Markovsky, A. Schechter, Y Ein Eli, and H. A. Cohen, J. Electrochem. Soc., 143, 3809 (1996).

30. D. Aurbach, MD Levi, E. Levi, and A. Schechter, J. Phys. Chem. B, 101, 2195 (1997).

31. M. Herstedt, A. M. Andersson, H. Rensmo, H. Siegbahn, and K. Edstrom, Electrochim. Acta, 49, 4939 (2004).

32. M. Herstedt, M. Stjerndahln, T. Gustafsson, and K. Edström, Electrochem. Comm. 5, 467 (2003).

33. E. Peled, D. Bar Tow, A. Merson, A. Gladkich, L. Burstein, and D. Golodnitsky, J. Power Sources, 97, 52 (2001).

34. M. Inaba, S.-K. Jeong, and Z. Ogumi, Electrochem. Soc. Interface, 20, 55 (2011).

35. A. M. Andersson, A. Henningson, H. Siegbahn, U. Jansson, and K. Edström, J. Power Sources, 119-121, 522 (2003).

36. B. Philippe, Doctoral thesis, Uppsala University and Pau University (2013).

37. B. Philippe, R. Dedryvère, M. Gorgoi, H. Rensmo, D. Gonbeau, and K. Edström, Chem. Mater, 25, 394 (2013).

38. B. Philippe, M. Valvo, F. Lindgren, H. Rensmo, and K. Edström, Chem. Mater. 26, 5028 (2014)

39. B. Philippe, A. Mahmoud, J.-B. Ledeuil, M. Chamas, K. Edström, R. Dedryvère, D. Gonbeau, and P.-E. Lippens, Electrochim. Acta, 123, 72 (2014). 
40. K. K. D. Ehinon, S. Naille, R. Dedryvere, P.-E. Lippens, J.-C. Jumas, and D. Gonbeau, Chem. Mater, 20, 5388 (2008)

41. S. Naille, R. Dedryvère, H. Martinez, S. Leroy, P.-E. Lippens, J.-C. Jumas, and D. Gonbeau, J. Power Sources, 174, 1086 (2007).

42. C. Marino, A. Darwiche, N. Dupré, H. A. Wilhelm, B. Lestriez, H. Martinez, R. Dedryvere, W. Zhang, F. Ghamouss, D. Lemordant, and L. Monconduit, J. Phys. Chem. C, 117, 19302 (2013).

43. R. Younesi, A. S. Christiansen, R. Scipioni, D.-T. Ngo, S. B. Simonsen, K. Edström, J. Hjelm, and P. Norby, J. Electrochem. Soc., 162, A1289 (2015).

44. L. Bodenes, R. Dedryvere, H. Martinez, F. Fischer, C. Tessier, and J.-P. Pérès, $J$. Electrochem. Soc., 159, A1739 (2012).

45. L. Bodenes, R. Naturel, H. Martinez, R. Dedryvère, M. Menetrier, L. Croguennec, J.-P. Pérès, C. Tessier, and F. Fischer, J. Power Sources, 236, 265 (2013).

46. S. S. Zhang, J. Power Sources, 162, 1379 (2006).

47. M. Herstedt, H. Rensmo, H. Siegbahn, and K. Edström, Electrochim. Acta, 49, 2351 (2004).

48. K. Ciosek Högström, H. Lundgren, S. Wilken, T. G. Zavalis, M. Behm, K. Edström, P. Jacobsson, P. Johansson, and G. Lindbergh, J. Power Sources, 256, 430 (2014).

49. H. Bouayad, Z. Wang, N. Dupré, R. Dedryvere, D. Foix, S. Franger, J.-F. Martin L. Boutafa, S. Patoux, D. Gonbeau, and D. Guyomard, J. Phys. Chem. C, 118, 4634 (2014).

50. L. El R. Ouatani C. Dedryvère P. Siret S. Biensan P. Reynaud D. Iratçabal J. Gonbeau Electrochem. Soc., 156, A103 (2009).

51. L. El Ouatani, R. Dedryvère, C. Siret, P. Biensan, and D. Gonbeau, J. Electrochem. Soc., 156, A468 (2009)

52. L. Martin, H. Martinez, M. Ulldemolins, B. Pecquenard, and F. Le Cras, Solid State Ionics, 215, 36 (2012)

53. C. Xu, F. Lindgren, B. Philippe, M. Gorgoi, F. Björefors, K. Edström, and T. Gustafsson Chem. Mater, 27, 2591 (2015).

54. K. Ciosek Hoögstroöm, S. Malmgren, M. Hahlin, H. Rensmo, F. Thébault, P. Johansson, and K. Edstroöm, J. Phys. Chem. C, 117, 23476 (2013).

55. K. Mizushima, P. C. Jones, P. J. Wiseman, and J. B. Goodenough, Mat. Res. Bull., 15, 783 (1980)

56. T. Ohzuku and M. Makimura, Chem. Lett., 30, 642 (2001).

57. A. K. Padhi, K. S. Nanjundaswamy, and J. B. Goodenough, J. Electrochem. Soc., 144, 1188 (1997).

58. R. Younesi, S. Malmgren, K. Edström, and S. Tan, J. Solid State Electrochem., 18 2157 (2014).

59. A. Gueguen, L. Castro, R. Dedryvere, E. Dumont, J. Breger, C. Tessier, and D. Gonbeau, J. Electrochem. Soc., 160, A387 (2013).

60. L. Baggetto, N. J. Dudney, and G. M. Veith, Electrochim. Acta, 90, 135 (2013).

61. L. Castro, R. Dedryvere, J.-B. Ledeuil, J. Breger, C. Tessier, and D. Gonbeau, J. Electrochem. Soc., 159, A357 (2012)

62. K. Ciosek Högström, S. Malmgren, M. Hahlin, M. Gorgoi, L. Nyholm, H. Rensmo, and K. Edström, Electrochim. Acta, 138, 430 (2014),

63. M. Wagemaker, R. van de Krol, A. P. M. Kentgens, A. A. van Well, and F. M. Mulder J. Am. Chem. Soc. 123, 11454 (2001).

64. R. van de Krol, A. Goossens, and E. A. Meulenkamp, J. Electrochem. Soc. 146, 3150 (1999).

65. M. Wagemaker, A. P. M. Kentgens, and F. M. Mulder, Nature (London) 418, 397 (2002).

66. R. J. Cava, D. W. Murphy, S. Zahurak, A. Santoro, and R. S. Roth, J. Solid State Chem. 53, 64 (1984).
67. A. Henningsson, H. Rensmo, A. Sandell, H. Siegbahn, S. Södergren, H. Lindström, and A. Hagfeldt, J. Chem. Phys. 118, 5607 (2003).

68. D. Tonti and R. Zanoni, Encyclopedia of Electrochemical Power Sources, p. 673 Elsevier, Amsterdam (2009).

69. J. H. Richter, A. Henningsson, P. G. Karlsson, M. P. Andersson, P. Uvdal, H. Siegbahn, and A. Sandell, Phys. Rev. B, 71, 235418 (2005).

70. R. Eriksson, K. Lasri, M. Gorgoi, T. Gustafsson, K. Edström, D. Brandell, I. Saadoune, and M. Hahlin, J. Phys. Chem. C, 119, 9692 (2015).

71. B. Philippe, R. Dedryvère, M. Gorgoi, H. Rensmo, D. Gonbeau, and K. Edström, $J$. Am. Chem. Soc., 135, 9829 (2013).

72. B. Philippe, A. Mahmoud, J.-B. Ledeuil, M. Chamas, K. Edström, R. Dedryvère, D. Gonbeau, and P.-E. Lippens, Electrochim. Acta, 123, 72 (2014).

73. H. Li, X. Huang, L. Chen, Z. Wu, and Y. Liang, Electrochem. Solid-State Lett., 2, 547 (1999).

74. J. Cabana, L. Monconduit, D. Larcher, and M. R. Palacín, Adv. Mater., 22, E170 (2010).

75. P. Poizot, S. Laruelle, S. Grugeon, L. DuPont, and J. M. Tarascon, Nature, 407, 496 (2000).

76. R. Dedryvere, S. Laruelle, S. Grugeon, P. Poizot, D. Gonbeau, and J.-M. Tarascon, Chem. Mater., 16, 1056 (2004)

77. R. Younesi, M. Hahlin, M. Treskow, J. Scheers, P. Johansson, and K. Edström, $J$. Phys. Chem. C, 116, 18597 (2012).

78. R. Younesi, S. Urbonaite, K. Edstroöm, and M. Hahlin, J. Phys. Chem. C, 116, 20673 (2012).

79. R. Younesi, M. Hahlin, and K. Edstroöm ACS Appl. Mater. Interfaces, 5, 1333 (2013).

80. L. Bodenes, A. Darwiche, and L. Monconduit,and H. Martinez, J. Power Sources, 273, 14 (2015).

81. M. A. Muñoz-Márquez, M. Zarrabeitia, E. Castillo-Martínez, A. Eguía-Barrio, T. Rojo, and M. Casas-Cabanas. ACS Appl. Mater. Interfaces, 7, 7801 (2015).

82. L. O. Vogt, M. El Kazzi, E. Jaömstorp Berg, S. Pérez Villar, P. Novák, and C. Villevieille, Chem. Mater, 27, 1210 (2015).

83. M. Dahbi, T. Nakano, N. Yabuuchi, T. Ishikawa, K. Kubota, M. Fukunishi, S. Shibahara, J.-Y. Son, Y.-T. Cui, H. Oji, and S. Komaba, Electrochem. Comm. 44, 66 (2014).

84. S. Södergren, H. Rensmo, and H. Siegbahn in I. Olefjord, L. Nyborg, and D. Briggs, ECASIA 97, Göteborg, Sweden, June 16-20, 1997. John Wiley \& Son Ltd: (1997).

85. H. Siegbahn and K. Siegbahn, J. Electron. Spectrosc. Relat. Phenom., 2, 319 (1973).

86. J. Schnadt, J. Knudsen, J. N. Andersen, H. Siegbahn, A. Pietzsch, F. Hennies, N. Johansson, N. Martensson, G. Ohrwall, S. Bahr, S. Mahl, and O. Schaff, J. Synchrot. Radiat. 19, 701 (2012).

87. S. K. Eriksson, M. Hahlin, J. M. Kahk, I. J. Villar-Garcia, M. J. Webb, H. Grennberg, R. Yakimova, H. Rensmo, K. Edstrom, A. Hagfeldt, H. Siegbahn, M. O. M. Edwards, P. G. Karlsson, K. Backlund, J. Ahlund, and D. J. Payne, Rev. Sci. Instrum. 85, 11 (2014).

88. D. F. Ogletree, H. Bluhm, G. Lebedev, C. S. Fadley, Z. Hussain, and M. Salmeron, Rev. Sci. Instrum. 73, 3872 (2002).

89. M. Salmeron and R. Schlogl, Surf. Sci. Rep., 63, 169 (2008).

90. J. Maibach, C. Xu, S. K. Eriksson, J. Åhlund, T. Gustafsson, H. Siegbahn, H. Rensmo, K. Edström, and M. Hahlin, Rev. Sci. Instrum. 86, 044101 (2015) 